\title{
Mechanisms of Seasonal Soil Moisture Drought Onset and Termination in the Southern Great Plains
}

\author{
Richard SeAger, Jennifer Nakamura, And Mingfang Ting \\ Lamont-Doherty Earth Observatory of Columbia University, Palisades, New York
}

(Manuscript received 7 September 2018, in final form 22 February 2019)

\begin{abstract}
Mechanisms of drought onset and termination are examined across North America with a focus on the southern Plains using data from land surface models and regional and global reanalyses for 1979-2017. Continental-scale analysis of covarying patterns reveals a tight coupling between soil moisture change over time and intervening precipitation anomalies. The southern Great Plains are a geographic center of patterns of hydrologic change. Drying is induced by atmospheric wave trains that span the Pacific and North America and place northerly flow anomalies above the southern Plains. In the southern Plains winter is least likely, and fall most likely, for drought onset and spring is least likely, and fall or summer most likely, for drought termination. Southern Plains soil moisture itself, which integrates precipitation over time, has a clear relationship to tropical Pacific sea surface temperature (SST) anomalies with cold conditions favoring dry soils. Soil moisture change, however, though clearly driven by precipitation, has a weaker relation to SSTs and a strong relation to internal atmospheric variability. Little evidence is found of connection of drought onset and termination to driving by temperature anomalies. An analysis of particular drought onsets and terminations on the seasonal time scale reveals commonalities in terms of circulation and moisture transport anomalies over the southern Plains but a variety of ways in which these are connected into the large-scale atmosphere and ocean state. Some onsets are likely to be quite predictable due to forcing by cold tropical Pacific SSTs (e.g., fall 2010). Other onsets and all terminations are likely not predictable in terms of ocean conditions.
\end{abstract}

\section{Introduction}

As winter approached in fall 2017, according to the U.S. Drought Monitor (http://droughtmonitor.unl.edu), severe to exceptional drought had been eliminated across the U.S. Southwest and southern Great Plains, and abnormally dry to moderate drought conditions were limited to coastal Southern California, the Mexican borderlands of Arizona, and a few other isolated areas. It was a remarkable state of hydrological normality amid two decades of heightened drought occurrence across the Southwest (Seager and Hoerling 2014). Alas, it was not to last. As winter began at the end of December, abnormally dry to severe drought was prevalent across the southwest apart from central to Northern California and, at the time of writing (September 2018), almost the entire region is dry, with much of the Four Corners states in extreme to exceptional drought. This drought has had agricultural impacts. For example, by 1 April 2018, in

Corresponding author: Richard Seager, seager@1deo.columbia.edu
Kansas, Oklahoma, and Texas, only $32 \%$ of winter wheat was reported in good or excellent conditions (Mercier 2018).

While the question of what is causing a drought is always of interest, for those impacted by drought, from farmers, power generators, forest fire fighters, to municipal authorities and householders among many others, this soon leads to questions of will the drought continue and when will it end? Alternatively, when there is no drought, stakeholders often ask when will the next drought occur? However climate science has advanced more in terms of being able to explain droughts than in being able to predict their onset and termination. While observational examinations of the connections between drought and the general circulation extend back a long way (e.g., Namias 1955), and modeling studies of individual droughts also have a long history (e.g., Trenberth et al. 1988), it was only just over a decade ago that causes of U.S. droughts were identified by analysis of long periods of observations and extended ensembles of simulations with climate models 
that allowed hypothesis testing (Schubert et al. 2004a,b; Herweijer et al. 2006; Seager et al. 2005, 2009) and also examination of seasonal ensemble hindcasts and forecasts of drought (Kumar et al. 2013). That work found that cold La Niña states of the tropical Pacific Ocean were the prime drivers of drought over the U.S. Southwest and Plains and that this influence extended over seasonal, interannual and decadal time scales (Huang et al. 2005; Schubert et al. 2008). A warm tropical North Atlantic Ocean also seems to be able to favor drought over the southwestern and central United States [consistent with the observational study of McCabe et al. (2004)] but is of secondary importance (Seager et al. 2008; Schubert et al. 2009).

While atmospheric circulation anomalies responding to sea surface temperature (SST) anomalies are a leading cause of North American droughts, land-atmosphere coupling can intensify and perhaps prolong droughts. Reductions in soil moisture can lead to reduced evapotranspiration, enhanced sensible and longwave radiative heat loss, reduced cloud cover and greater surface solar radiation which collectively lead to higher surface air temperatures. Over North America this land-atmosphere coupling is especially strong in the Great Plains and in the warm season (Koster et al. 2004; Dong et al. 2011; Ford et al. 2017; Basara and Christian 2018) with spring soil moisture initial conditions offering the potential for limited predictability of subsequent summer precipitation (Meng and Quiring 2010a,b; Basara and Christian 2018). However, landatmosphere coupling can alter the evolution of drought but is unlikely to initiate or terminate drought.

Despite advances in understanding the oceanic causes of droughts, it is not clear how much this influence translates into understanding the causes of onsets and terminations of droughts. There is reason to be doubtful about whether it does. In a review of causes of North American droughts, Seager and Hoerling (2014) emphasized the important role for internal atmospheric variability in causing some droughts and the limited, though still very important, role for ocean driving. Kumar et al. (2013) found no ocean influence on the 2012 Great Plains drought. And in another cautionary tale, the massive El Niño of winter 2015/16 was confidently expected to alleviate, and possibly terminate, the California drought that began in winter 2011/12 but spectacularly failed to do so with potent internal atmosphere variability being one explanation among many (Jong et al. 2016; Siler et al. 2017).

Surprisingly, with some exceptions, the physical mechanisms of drought onset and termination (hereafter DO\&T) across North America have not received a great amount of attention. To examine this requires analysis of change over time, as opposed to the value at any one time, of hydrological quantities and how these relate to, say, atmosphere circulation and SSTs. Time differentiation is a high-pass filter so we immediately expect the relations to be potentially clouded by "noise." However, if we are interested in the actual mechanisms of DO\&T this "noise" is actually signal: it may be that high-frequency variability in the climate system is responsible for DO\&T even as SSTs variations guide the overall time variations of drought and pluvial on the longer seasonal to decadal time scales.

The area of research of drought termination for which there has been considerable work concerns atmospheric rivers. These are narrow streams of high moisture content air associated with synoptic weather systems that often transport moisture from the subtropics to midlatitudes. When these streams interact with the coastal topography of the U.S. West Coast they can cause extreme high precipitation, sometimes so high that persistent droughts can be terminated in a few weather events (see, e.g., Dettinger 2013, 2016). In addition there has been work on how tropical cyclones can contribute to drought relief or termination in the southeast United States (e.g., Kam et al. 2013; Maxwell et al. 2013). In more general prior work on DO\&T, Karl et al. (1987) noted that the probability of amelioration or termination of a drought depends on the mean annual cycle of precipitation, being highest in wet seasons that have the possibility of extreme wet conditions. Mo (2011) noted that drought onsets are expected to be slower than terminations with soil moisture deficits often taking seasons to develop into droughts. For the southern Plains, Mo (2011) noted that La Niña events could be a useful early warning of drought onset, a matter we return to here. Dettinger (2013) argued that drought onsets are slower than terminations because negative precipitation anomalies cannot exceed the negative of the climatological precipitation, but positive anomalies easily can. However, Maxwell et al. (2017) specifically studied rapid drought terminations at the local scale across the southeast United States. For this region they found that rapid termination was most likely in summer and fall with fronts and tropical cyclones the two most likely causes and atmospheric rivers responsible for considerably fewer terminations.

In this paper we take a new approach to examine the mechanisms of DO\&T over North America, focusing in on the southern Plains. Since the answer to our first question draws attention to the southern Plains, the remaining questions focus on that region.

(i) Are there coherent large-scale patterns of soil moisture change over time on seasonal time scales that 
connect to patterns of precipitation anomalies? How are the precipitation anomalies that drive soil moisture change over time connected to large-scale atmosphere circulation anomalies and, potentially, SST anomalies?

(ii) In the southern Plains, how is soil moisture change related to changes in precipitation, runoff, and temperature (which influence atmospheric moisture demand and evapotranspiration)? How are these correlations themselves related to large-scale changes in atmosphere circulation, moisture transports and SSTs?

(iii) For the southern Plains and particular cases of DO\&T, what are the causes and how are they related to anomalies in the atmosphere circulation and, potentially, driving from SSTs?

In this study we focus on seasonal time-scale DO\&T. Such events evolve fast enough that they could have serious social and economic impacts if not predicted and adapted to and are also potentially predictable with operational seasonal prediction systems. In this study we do not consider even faster evolving, so-called "flash drought" that can arise from either warm temperatures driving high evapotranspiration or, more commonly, precipitation deficits (Mo and Lettenmaier 2016). This is a purely observational study, and we begin by detailing the observational datasets used. We then describe the results of analyses that seek to examine general relations between changes in land hydrology and atmospheric forcing before focusing in on the southern Plains for further analysis. We then identify the mechanisms of DO\&T for the southern Plains and finish by analyzing a series of case studies of DO\&T over past decades before offering a discussion and conclusions.

\section{Data and methods}

\section{a. Observational data used}

The quantity we use to assess DO\&T is soil moisture in the upper layers of the land surface. Since direct soil moisture measurements are few and far between, we use soil moisture computed by calibrated land surface models (LSMs) forced by observed and reanalysis atmospheric conditions. Here we use three LSMs that collectively make up the North American Land Data Assimilation System Version 2 (NLDAS-2) database (Xia et al. 2012a,b; http://ldas.gsfc.nasa.gov/index.php). These are physical models of the upper layers of the land surface that solve equations for the transfer of heat and moisture at the surface and between layers in the soil. The models include representation of vegetation and how it interacts with the atmosphere and soil. Atmospheric conditions-air temperature, air humidity, radiative fluxes, wind speed-are imposed from the North American Regional Reanalysis (NARR; Mesinger et al. 2006) while precipitation forcing comes from daily Climate Prediction Center gauge observations using the topographic adjustment method of the PRISM group (Daly et al. 2000; for details see https://ldas.gsfc.nasa.gov/ nldas/NLDAS2forcing.php\#AppendixC). The LSMs are the Noah, Mosaic, and VIC models. We use soil moisture in the upper $1 \mathrm{~m}$, which is a depth relevant to roots of crops and plants and is common to all three LSMs. Given that it would be unwieldy to show results from all three, guided by the validation work in Xia et al. (2014), for analysis of soil moisture change over time we focus on the Noah model. However, for analysis of DO\&T, that is, discrete events, we only examine results from Noah for cases where there is agreement across at least two (including Noah), and where possible all three, LSMs that these are in fact DO\&Ts.

The simulation of soil moisture in the NLDAS-2 models has been validated against in situ soil moisture measurements by Xia et al. (2014, 2015). Given our focus on the southern Great Plains, the comparison of NLDAS-2 models to the Oklahoma Mesonet in situ measurements of soil moisture for 1997-2002 is most relevant. The correlation coefficients between the 72 monthly values of Mesonet observed and Noah model simulated $0-10-, 10-40-$, and $40-100-\mathrm{cm}$ soil moisture are $0.86,0.88$, and 0.87 , respectively (Xia et al. 2014; Table 1) with the time histories showing good correlation of wet and dry months during this period (Xia et al. 2014; Fig. 12). Xia et al. (2014) also compared the model simulated soil moisture to the observations from the U.S. Department of Agriculture Soil Climate Analysis Network (http://www.wcc.nrcs.usda.gov) for a wider Great Plains region and the models had similar skill as for the Oklahoma Mesonet comparison. Of the NLDAS-2 models Noah is consistently performing well justifying its selection here for further analysis. It should be noted that the NLDAS-2 LSMs do not contain vegetation dynamics and hence will not represent how soil moisture responds to changes in vegetation during DO\&Ts.

To examine the atmosphere context of DO\&T we use geopotential heights and moisture transports from NARR (https://www.ncdc.noaa.gov/data-access/model-data/ model-datasets/north-american-regional-reanalysis-narr). To examine the large-scale context we use geopotential heights and SSTs from the National Centers for Environmental Prediction-National Center for Atmospheric Research (NCEP-NCAR) Reanalysis (https:// iridl.ldeo.columbia.edu/SOURCES/.NOAA/.NCEP-NCAR/ .CDAS-1/.MONTHLY/?Set-Language=en). Precipitation data used throughout are the forcing data for the 
TABLE 1. Identified DO\&Ts for three NLDAS-2 LSMs. If two models agree on the season the date is in italic, and if three models agree the date is in bold.

\begin{tabular}{|c|c|c|c|c|}
\hline & OND & JFM & AMJ & JAS \\
\hline \multicolumn{5}{|c|}{ Drought onset } \\
\hline Noah & 1989, 1995, 2003, 2005, 2010, 2017 & & 1980, 1998, $\mathbf{2 0 1 2}$ & $1983,1999,2000$ \\
\hline Mosaic & 1989, 1995, 1999, 2005, 2010, 2017 & & 2012 & \\
\hline VIC & $1985, \mathbf{2 0 0 5}, 2008, \mathbf{2 0 1 0}$ & & 1980, 1998, 2012 & 1979, 1992, 2000, 2015, 2017 \\
\hline \multicolumn{5}{|c|}{ Drought termination } \\
\hline Noah & 1983, 2000, 2011 & 1990, 2004 & & 2006,2013 \\
\hline Mosaic & 2000 & 1990 & 1981 & 1996,2006 \\
\hline VIC & 1979, 1992, 2000, 2015 & 2000 & 1996 & 1980, 1998, 2011, 2012 \\
\hline
\end{tabular}

NLDAS-2 LSMs (see above). The period covered is that of NLDAS-2 from January 1979 to December 2017. We analyze seasonal means of October-December (OND), January-March (JFM), April-June (AMJ), and JulySeptember (JAS), as well as instantaneous values of soil moisture on 1 October, 1 January, 1 April, and 1 July computed as the average of before and after monthly values. Much analysis is done on soil moisture change, which is the soil moisture at the beginning of one season minus that at the beginning of the previous season. So, for example, letting $s_{m}$ be soil moisture, $s_{m}$ (1 October) $=0.5 s_{m}$ (October $)+0.5 s_{m}$ (September) and $s_{m}$ change over OND equals $s_{m}$ (1 January) $-s_{m}$ (1 October).

\section{b. Methods}

To identify covarying patterns between soil moisture change and precipitation across the United States, we use canonical correlation analysis (CCA) on the two fields. CCA begins by performing empirical orthogonal function (EOF) analysis on the two individual fields. The eigenvalue sequence for each was examined and only those EOFs with large eigenvalues and which had a clear break from the rest of the eigenvalues and which were significant according to Preisendorfer's Rule N were retained. This performs a filtering of the two fields. The CCA then identifies within the filtered fields the patterns of (i) soil moisture change and (ii) precipitation in the intervening season whose associated time series best correlate together in time. We only show results for the first pair of patterns for which the correlation coefficients between the two time series are significant above the $1 \%$ level. It should be noted that the methodology does not ensure a physical consistency between soil moisture change over time and precipitation and that, while these are in general consistent, inconsistencies can appear in some locations within the patterns. To perform the EOFs and CCA the NLDAS-2 data were regridded from $1 / 8^{\circ}$ to $1 / 2^{\circ}$ and data in Canada, which are often discontinuous with data across the border in the United States, were excluded. The time series associated with the precipitation pattern is used to regress geopotential heights from NARR and NCEPNCAR as well as SST on to examine the large-scale associated climate anomalies.

After the cross-U.S. analysis we focus on the southern Plains, which is defined (rather broadly) as $30^{\circ}-40^{\circ} \mathrm{N}$, $110^{\circ}-90^{\circ} \mathrm{W}$, and area averages of soil moisture, soil moisture change and precipitation are created for this region. The resulting time series of seasonal values are used to regress atmosphere and ocean quantities (heights, moisture transports, SSTs) on. To examine relations between quantities in the region we create scatterplots of southern Plains soil moisture at the beginning and end of seasons and plot together with intervening seasonal precipitation, runoff and temperature. Criteria for DO\&T are determined on standardized soil moisture time series for the area average. Mo (2011) has shown how soil moisture anomalies follow a normal distribution, and this was assumed to perform the standardization. The DO\&T identification procedure is as follows:

- Drought onset. The standardized soil moisture at end of season is less than -1 , at beginning greater than -1 , and the change over the season (e.g., from 1 October to 1 January) is more negative than -1 . That is, the soil moisture began in the normal or wet range (above negative one standard deviation), ended in the dry range (below negative one standard deviation) and changed in the dry direction by more than one standard deviation.

- Drought termination. The standardized soil moisture at end of season is more than -1 , at beginning less than -1 and the change over the season is greater than 1. That is, the soil moisture began in the dry range (below negative one standard deviation), ended in the normal or wet range (above negative one standard deviation) and changed in the wet direction by more than one standard deviation.

This is done for each of the three LSMs, and Table 1 lists the DO\&Ts identified in each LSM. The case studies of 
DO\&T are then ones for which there is cross-LSM agreement. For onset we were able to enforce that all three models agree, which gave us three onsets. To identify three terminations we had to relax this to two LSMs agreeing. The six DO\&Ts are marked in Table 1. Because, to be identified as a DO\&T according to these criteria the soil moisture change must exceed one standard deviation in amplitude, not all drought onsets need to be coupled with a drought termination. For example, a one season drought onset may be followed by a transition of soil moisture back to normal conditions that occurs sufficiently gradually that no seasonal time-scale termination is identified. Alternatively, a gradual move into drought could be followed by a one season change that is identified as a drought termination by our criteria. Our focus here is on seasonal DO\&T so this lack of requirement for coupling of onset and termination is appropriate.

\section{Results}

Covarying patterns of anomalies in soil moisture change and precipitation across the United States and associated climate anomalies

Figures 1-4 show the results of the CCA analysis proceeding through the hydrologic year from OND to JAS. The figures indicate at top how many modes of soil moisture change and precipitation were retained in the EOF filtering before the CCA was conducted, and it varies from 2 to 6 . For all seasons the CCA analysis returns patterns of soil moisture change and precipitation whose associated time series are well correlated (correlation coefficients of 0.74 for OND, 0.82 for JFM, 0.75 for AMJ, 0.71 for JAS, all significant at the $1 \%$ level according to a two-sided $t$ test).

For OND (Fig. 1), the CCA returns patterns of continental-scale soil moisture change over time and precipitation that are well related in space. As shown, a decline in fall soil moisture occurs over the southern United States. from coast to coast and stretching up into the central Plains with the strongest decline in Texas, and is associated with a similarly broad negative precipitation anomaly centered in the Gulf states. This southern drying goes along with wetting (higher precipitation and soil moisture increases) in the Pacific Northwest. From the Midwest to the Northeast the results are inconsistent with soil moisture increase but precipitation decline. This pattern can be thought of as one that could induce drought onset in the southern United States in fall. It is well associated with a Rossby wave train with a high-low dipole centered over southwest-southeast North America (Fig. 1d).
This wave pattern places strong northerly flow over the southern Plains, which will induce drying via dry advection and subsidence and, together with a low over the Gulf of Alaska, place southwesterly flow over the Pacific Northwest inducing higher precipitation. Looking at the global scale (Fig. 1e), the wave train appears to originate in the tropical west Pacific and might be influenced by cold SST anomalies in the eastern tropical Pacific. The SST anomaly pattern is clearly La Niña-like but the height pattern is not a classic La Niña for this season (see Seager et al. 2014a).

The patterns for JFM (Fig. 2) divide the continent into declining soil moisture in the interior southwest and increasing across the north and east. The southwest region of soil moisture decline is associated with negative precipitation anomalies, and there are regions of positive precipitation anomalies in the interior northwest and eastern United States. The Pacific Northwest and Florida stand out as regions of soil moisture increase but reduced precipitation, which may not be physically consistent. The associated height patterns (Fig. 2d) have high pressure over the Gulf of Alaska and stretching across the U.S. West Coast and northern Mexico. This is consistent with the precipitation anomaly pattern with reduced moist air inflow to the northwest and dry northwesterly flow under high pressure across the interior southwestern United States and Gulf states. The global-scale pattern (Fig. 1e) is typical for winters with La Niña influenced cool SSTs: low heights over the tropical Pacific and a wave train extending poleward and eastward (Seager et al. 2014b).

In AMJ (Fig. 3) a pattern of declining soil moisture across the entire central United States and most of the east is associated with a similarly located pattern of negative precipitation anomalies, while the Pacific Northwest has positive precipitation anomalies and an increase in soil moisture. Once more, these patterns have clear relations to Rossby wave trains with lows over British Columbia and the U.S. Southeast and a high over northern Mexico that combine to reduce moisture inflow to the central United States and increase it into the Pacific Northwest. Unlike for fall and winter the Rossby wave train extends around the entire hemisphere (Fig. 3e) and does not have an obvious source in the tropical Pacific despite continuing $\mathrm{La}$ Niña conditions in the tropical Pacific.

In JAS (Fig. 4) there is a pattern of soil moisture decline centered on the southern Plains and extending to the central Plains and across the eastern United States that goes along with a similarly located negative precipitation anomaly. There are positive precipitation anomalies and increasing soil moisture across the entire west to the west of $110^{\circ} \mathrm{W}$. The precipitation pattern is related to a Rossby wave in a consistent way with a high 


\section{CCA OND Four Soil Moisture Change, Two Precip, Mode 1}

a) SM Structure

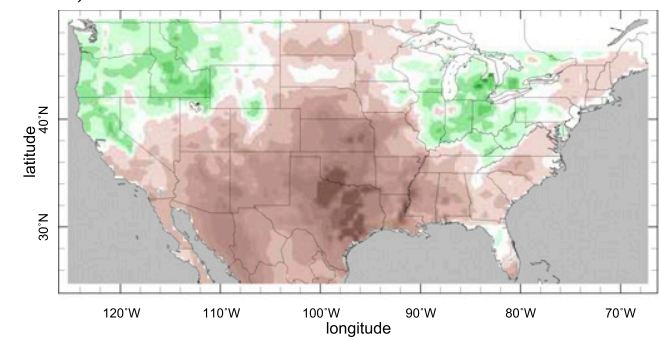

b) Precip Structure

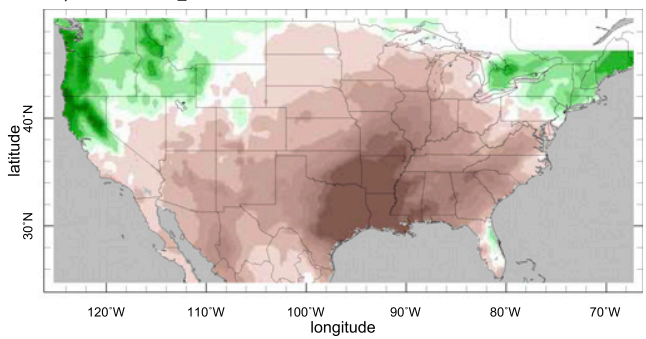

1.0

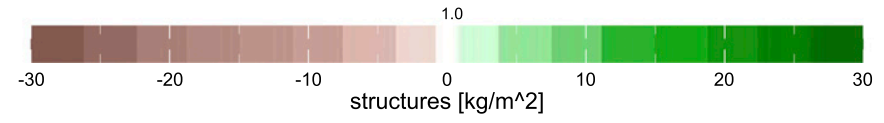

c) Time series corr 0.74

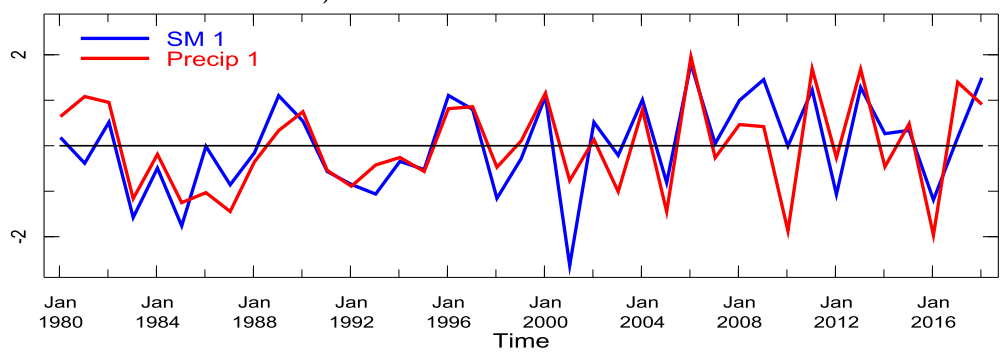

Regression OND CCA SM and Precip PR PC1 with OND

\section{d) NARR 700mb Height}

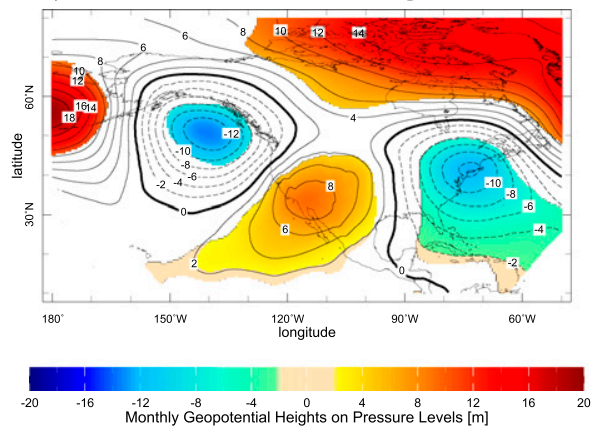

e) NCEP SST (color) 700mb Z (contour)

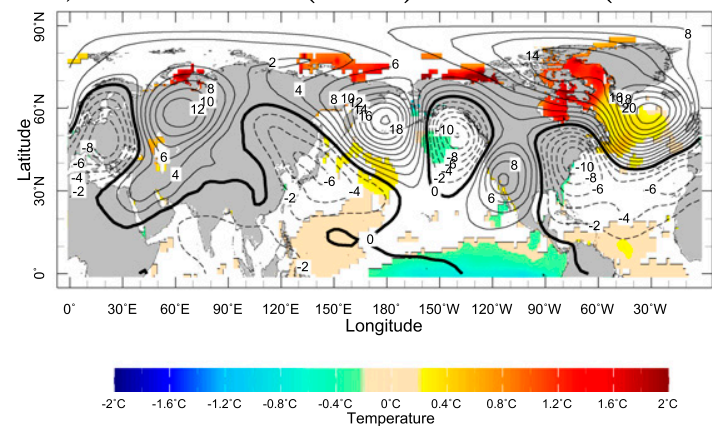

FIG. 1. Results from the seasonal CCA analysis of PRISM precipitation and change over time of NLDAS-2 Noah soil moisture for OND. (a) The pattern of soil moisture change $\left(\mathrm{kg} \mathrm{m}^{-2} \mathrm{month}^{-1}\right)$ over OND and (b) the associated pattern of precipitation $\left(\mathrm{kg} \mathrm{m}^{-2}\right.$ month $\left.^{-1}\right)$ during OND. (c) The two corresponding time series and their correlation coefficient. (d) The correlation of the precipitation time series with 700-mb height (m) from the NARR regional reanalysis and (e) the correlation with the NCEP-NCAR 700-mb heights and SST (K). The number of EOF modes retained for each field to enter the CCA analysis is indicated in the top panel title. The time series are standardized.

anomaly over the southern Plains and a low anomaly over the west coast that is part of a hemispheric-scale wave train and without obvious tropical driving (Figs. 4d,e).

The identified patterns are of genuine physical relevance. The spatial patterns of variance associated with the leading modes are computed from the longitude, latitude, and time field derived by combining the spatial patterns (Figs. 1a,b-4a,b) with the time series (Figs. 1c-4c).
In Fig. 5 we show the fraction of the total variance of soil moisture change and precipitation explained by the leading modes from the CCA analysis. For the southern Plains in OND the modes explain more than half the variance. The modes also can explain more than a third of the variance in the southern Plains and central southern United States in AMJ and JAS too and in JFM for precipitation but not for soil moisture change. 


\section{CCA JFM Four Soil Moisture Change, Six Precip, Mode 1}

a) SM Structure

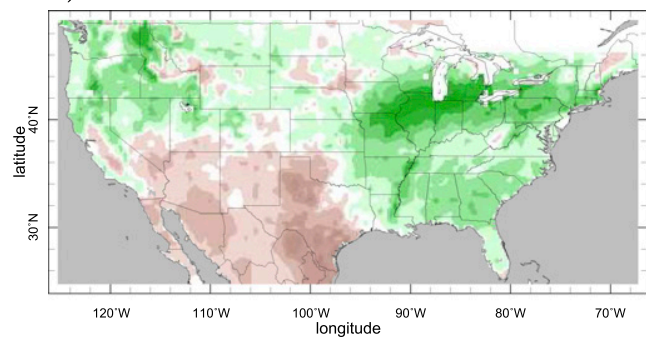

b) Precip Structure
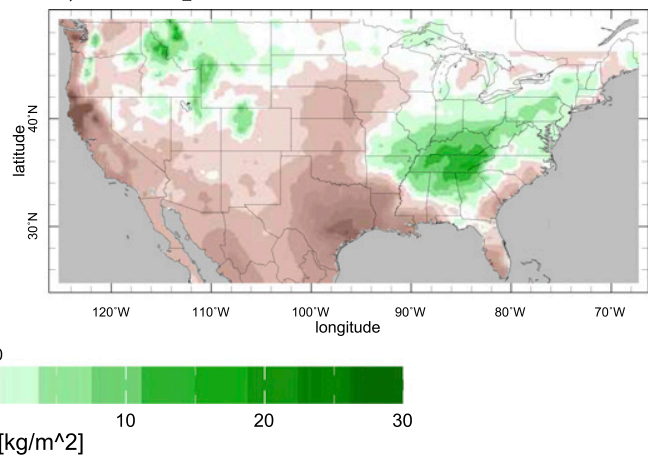

c) Time series corr 0.82

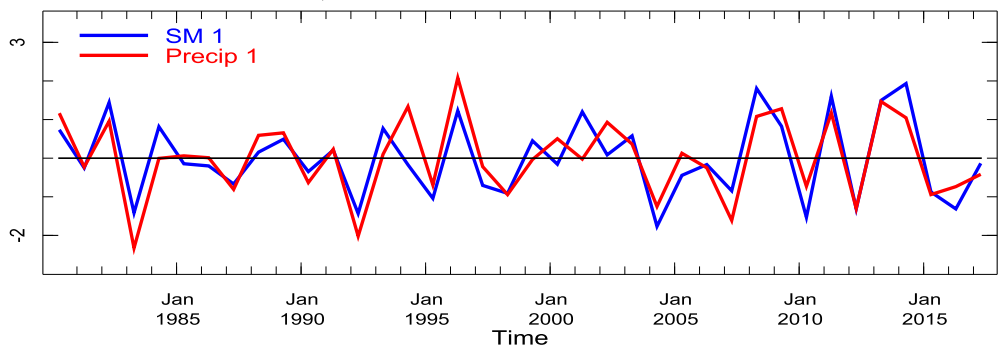

1.0

\section{Regression JFM CCA SM and Precip PR PC1 with JFM}

d) NARR 700mb Height

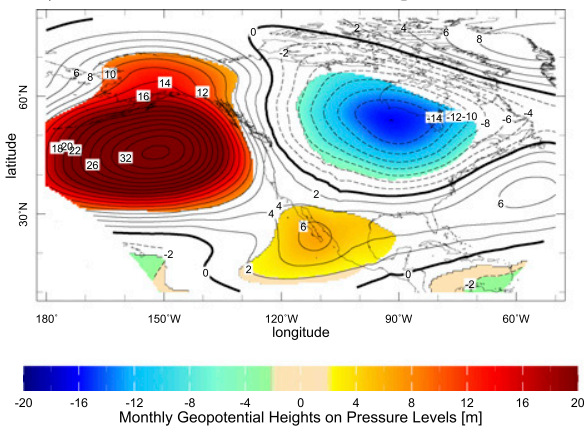

e) NCEP SST (color) 700mb Z (contour)

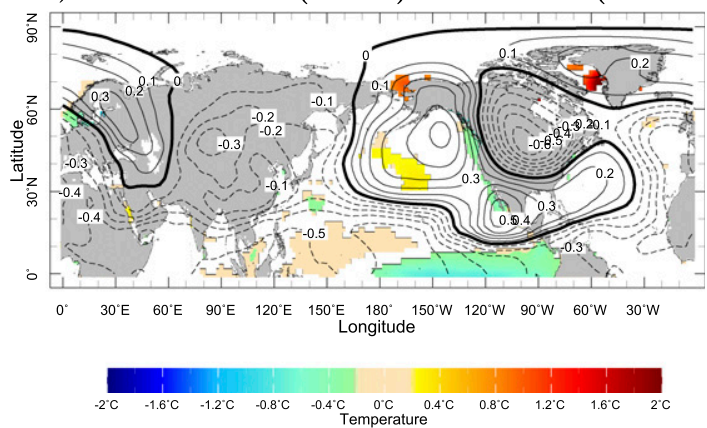

FIG. 2. As in Fig. 1, but for JFM.

These results make clear that, for the general case of change in soil moisture over a season, it is related to continental-scale changes in surface hydrology and precipitation that occur in the context of planetaryscale circulation anomalies with likely influence from the tropical Pacific Ocean in fall and winter. The soil moisture changes are therefore highly spatially coherent and systematic in their origin. The results also make clear that the southern Plains stand out as an epicenter of surface hydrology change that are impacted in all seasons by circulation anomalies that can drive soil moisture anomalously high or low and where large fractions of total variance of both soil moisture change and precipitation are contained within the leading CCA mode. In the remainder we therefore turn our focus to general change and DO\&T in the southern Plains.

\section{Relation of soil moisture change over the southern Plains to components of the surface water balance}

Soil moisture change over time is not just related to precipitation. The prognostic equation for soil moisture is $(d / d t) \int_{-D}^{0} s_{m} d z=P+S-\mathrm{ET}-R$, where $D$ is some depth $(\mathrm{m}), s_{m}$ is soil moisture $\left(\mathrm{kg} \mathrm{m}^{-3}\right)$, and $P$ is 


\section{CCA AMJ Two Soil Moisture Change, Four Precip, Mode 1}

a) SM Structure

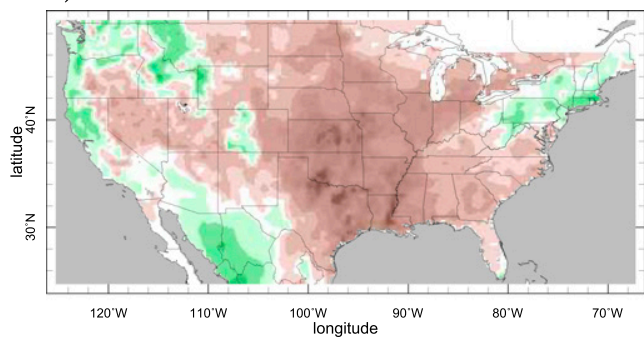

b) Precip Structure

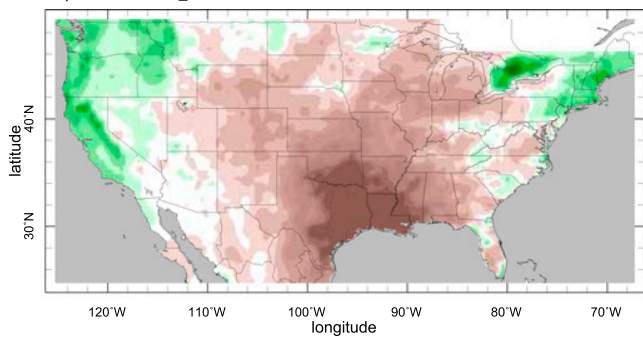

1.0

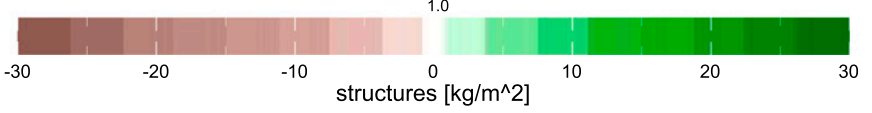

c) Time series corr 0.75

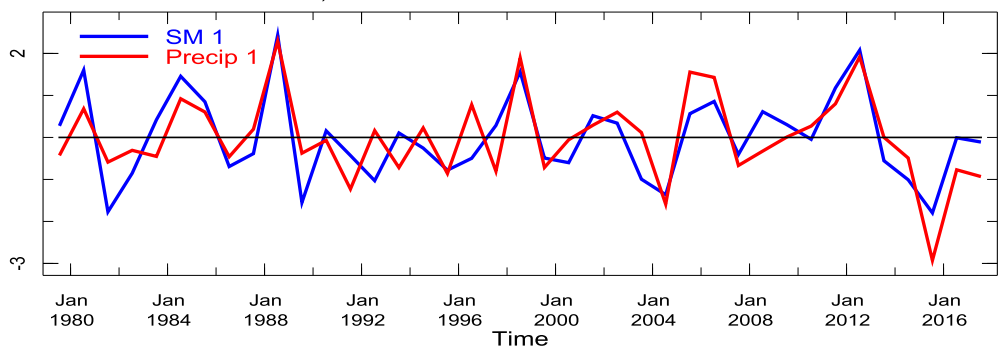

1.0

\section{Regression AMJ CCA SM and Precip PR PC1 with AMJ}

d) NARR 700mb Height

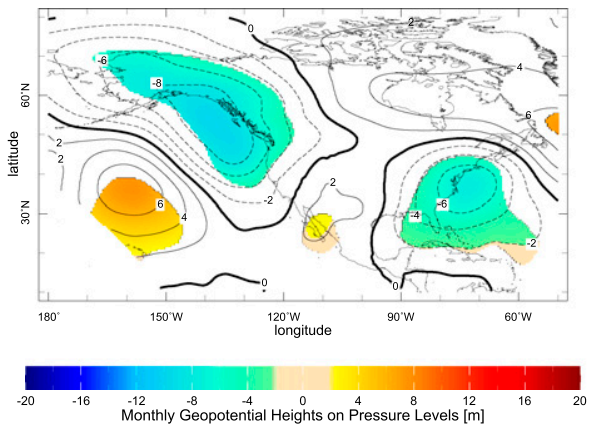

e) NCEP SST (color) 700mb Z (contour)

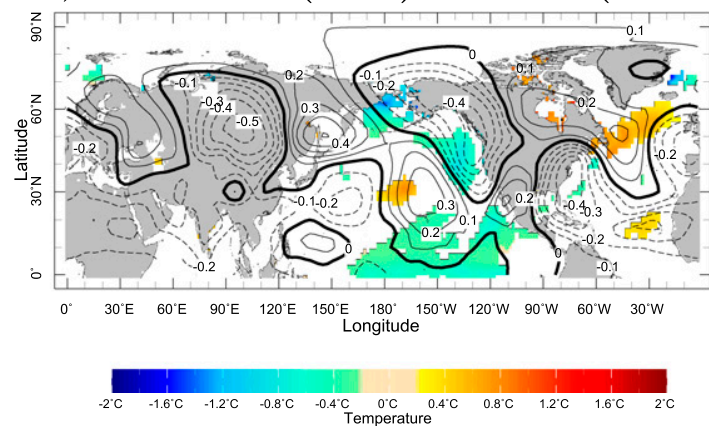

FIG. 3. As in Fig. 1, but for AMJ.

precipitation in the form of rain, $S$ is snowmelt, ET is evapotranspiration, and $R$ surface plus subsurface runoff (all in $\mathrm{kg} \mathrm{m}^{-2}$ month ${ }^{-1}$ ). In this analysis for the southern Plains we draw no distinction between rain and snow and implicitly assume all precipitation is available to enter the soil as soon as it falls. The ET is influenced by the vapor pressure deficit of the atmosphere $e_{s}-e_{a}$, which is the difference between the actual vapor pressure of the atmosphere $e_{a}$ and the saturation value $e_{s}$ and is a measure of how much moisture the atmosphere could remove from the surface. ET is also influenced by the amount of moisture there is in the soil $s_{m}$ and will go to zero if the soil dries out completely, and is also influenced by the ability of plants to regulate water loss during photosynthesis when stomatae are open, and by aerodynamic resistances in the canopy and the atmospheric boundary layer. Despite this complexity, we do expect high temperatures to create a tendency to higher ET as long as some soil moisture remains, while the resulting soil moisture drawdown and plant physiological response will oppose this tendency.

In Figs. 6-8 we plot the soil moisture at the beginning of the season (vertical axis) against that at the end of the season (horizontal axis) together with the precipitation, runoff and temperature during the intervening season. Everywhere above the 1:1 line corresponds to seasonal 


\section{CCA JAS Three Soil Moisture Change, Five Precip, Mode 1}

a) SM Structure

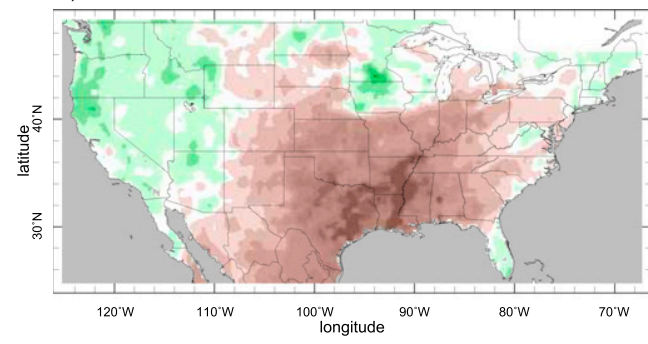

b) Precip Structure

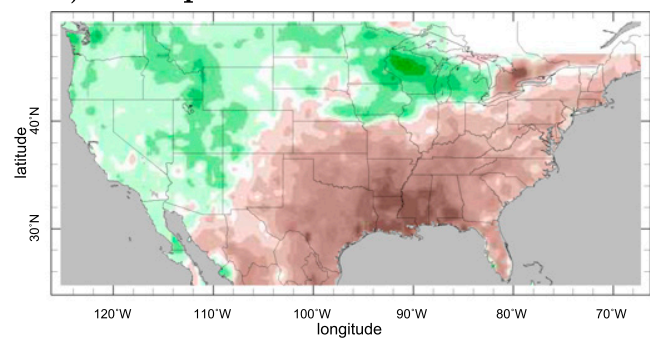

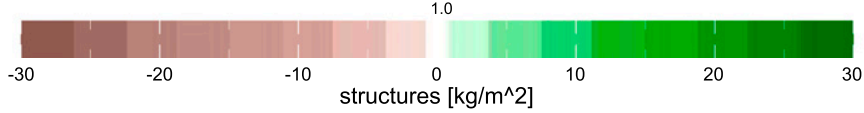

c) Time series corr 0.71

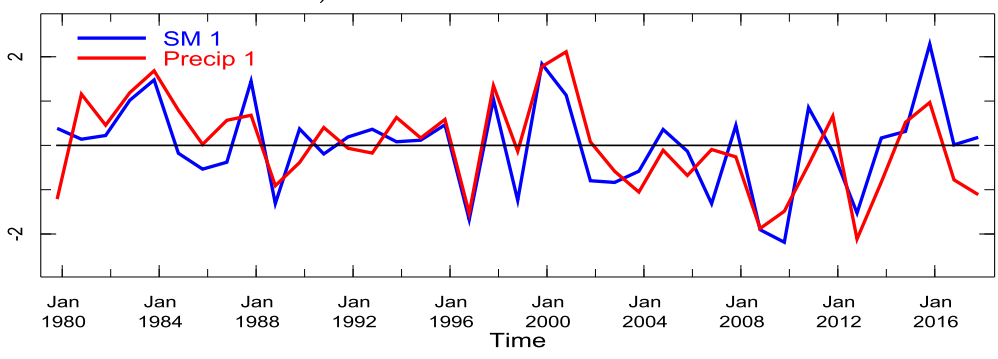

Regression JAS CCA SM and Precip PR PC1 with JAS

d) NARR 700mb Height

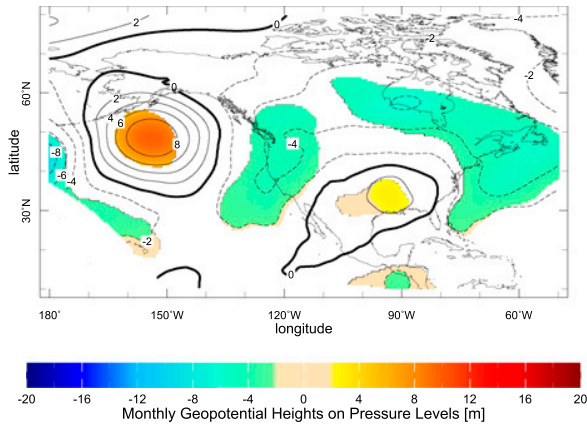

e) NCEP SST (color) 700mb Z (contour)

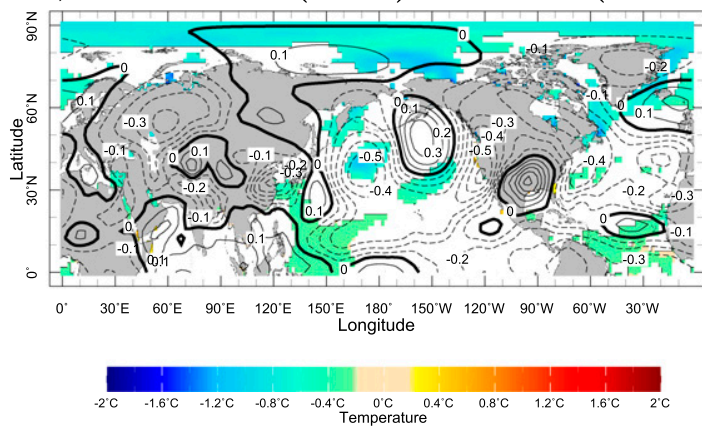

FIG. 4. As in Fig. 1, but for JAS.

drying of the soils and everywhere below to wetting. The areas in soil moisture space that correspond to DO\&T are contained within the marked areas in the upper-left and lower-right parts of the figures. If the transition is an onset it is marked by a plus $(+)$ sign and if a termination by an ex $(\times)$ sign. Though the results shown are for the Noah model alone, a box is drawn around the DO\&Ts if there is three LSM agreement for onsets and two LSM agreement for terminations.

One result that stands out in each figure is that there is a marked tendency for less change in soil moisture during JFM than in the other seasons (i.e., data lie closer to the 1:1 line in JFM). In contrast, OND stands out as a common season for both drought onset and termination but JAS and OND are also seasons for drought onset but no terminations have occurred in AMJ. There is a very clear association of drying (wetting) and drought onset (termination) with positive (negative) precipitation anomalies in the intervening season (Fig. 6) though this relation is by no means absolute. For example, in JFM there are a cluster of seasons of transition from wet to less wet conditions (upper-right quadrant) that went along with positive precipitation anomalies. However, for actual DO\&T, the sign of soil moisture change is always consistent with that of precipitation change, indicating precipitation driving. 


\section{Seasonal CCA Soil Moisture Change (SM) and Precip, SM (left) Precip (right)}

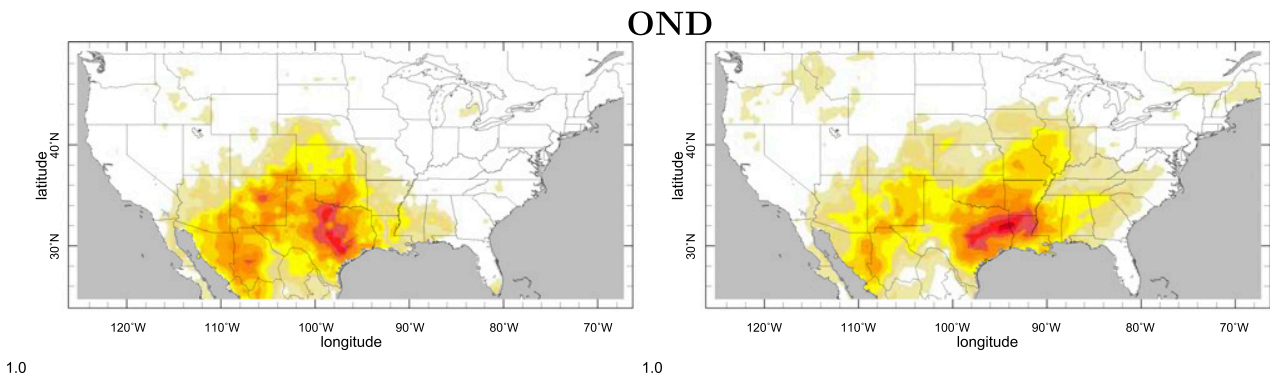

JFM
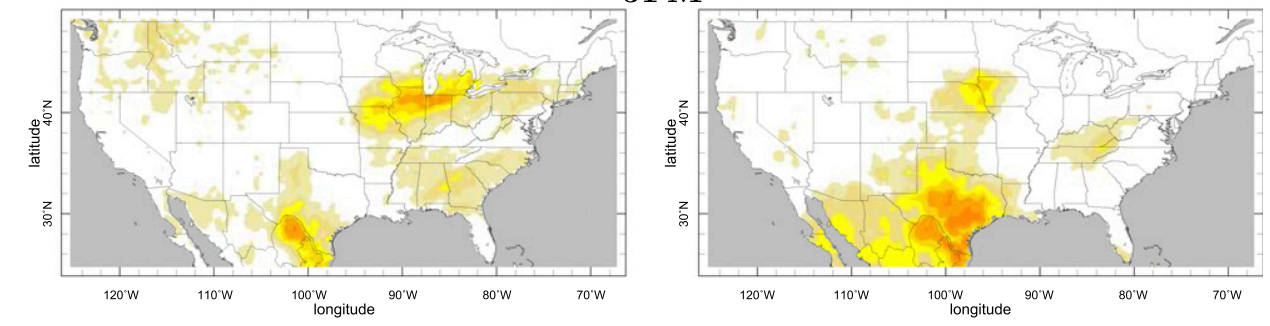

1.0

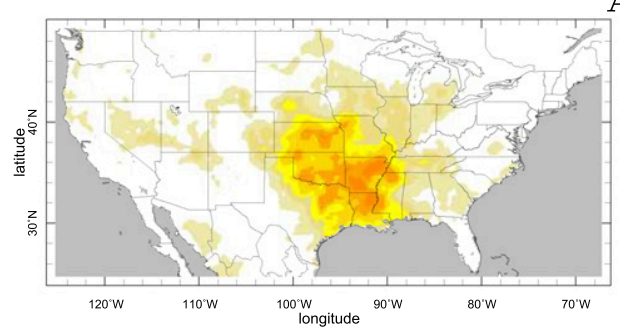

AMJ
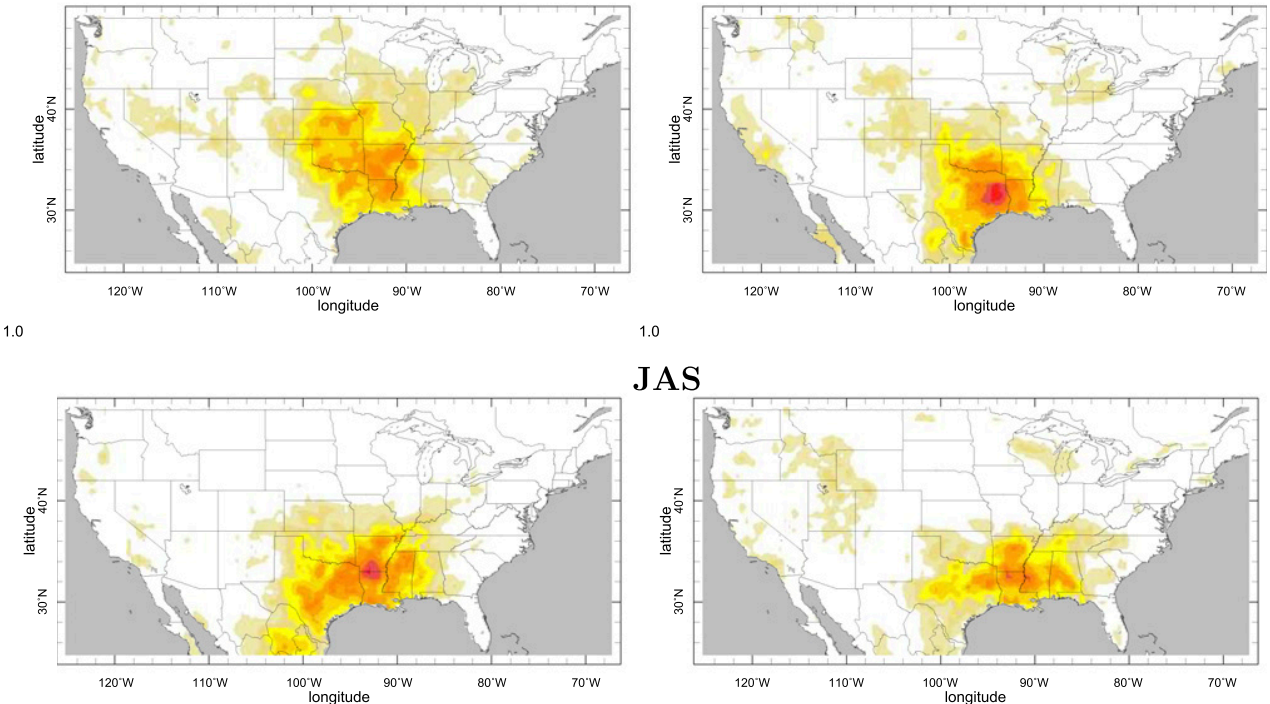

JAS

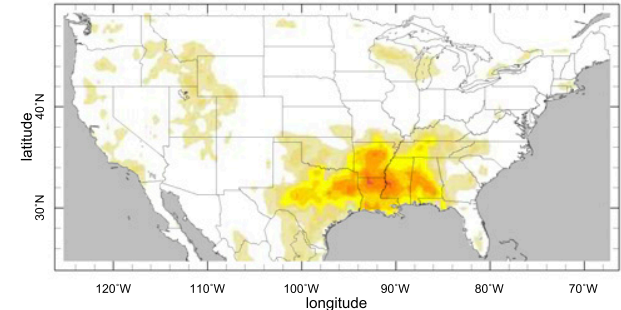

1.0

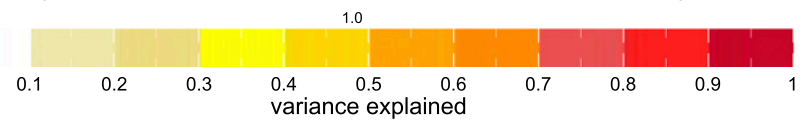

FIG. 5. The fraction of total variance of (left) soil moisture change and (right) precipitation that is explained by the first mode from the CCA analysis for each season from (top) OND to (bottom) JAS.

Looking at the relation between change in soil moisture and runoff (Fig. 7), we see that the cluster of JFM data with a dry transition in soil moisture but positive precipitation anomalies go along with an increase in runoff. Although we have not investigated these seasons more closely since they are not ones of DO\&T, for some reasons, perhaps intense precipitation, the excess water delivered by the atmosphere went into runoff and negative anomalies in infiltration and soil moisture change. For the DO\&T events, all onsets went along with reduced runoff while terminations had either increased or decreased runoff. Physically, together with the results for precipitation, this suggests a decline in precipitation can cause drought onset as measured by reduced soil moisture but will also lead to a reduction in runoff. However, an increase in precipitation leading to 


\section{Seasonal Southern Plains NOAH Std SM Change, Avg Precip (color) \\ OND}
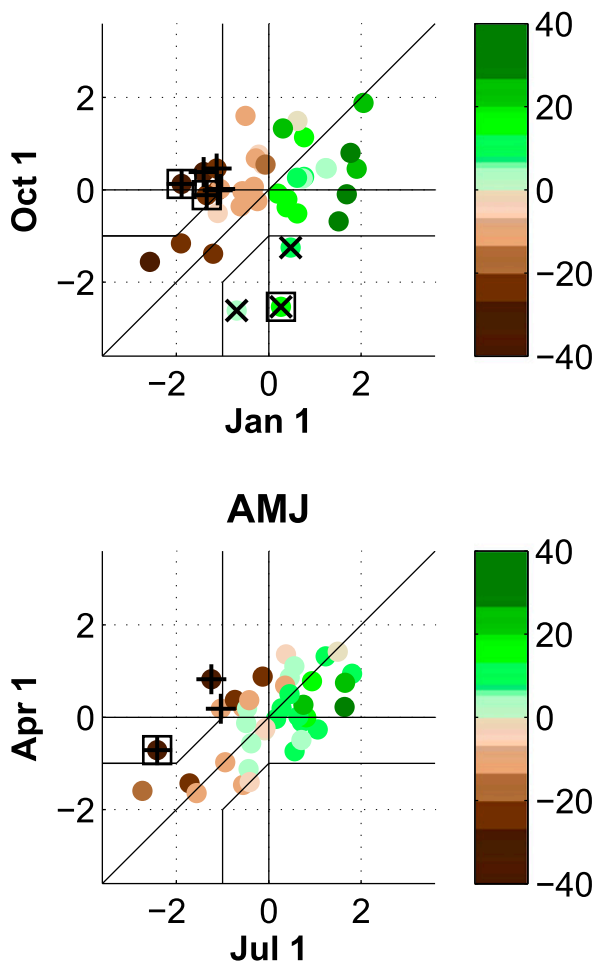

JFM
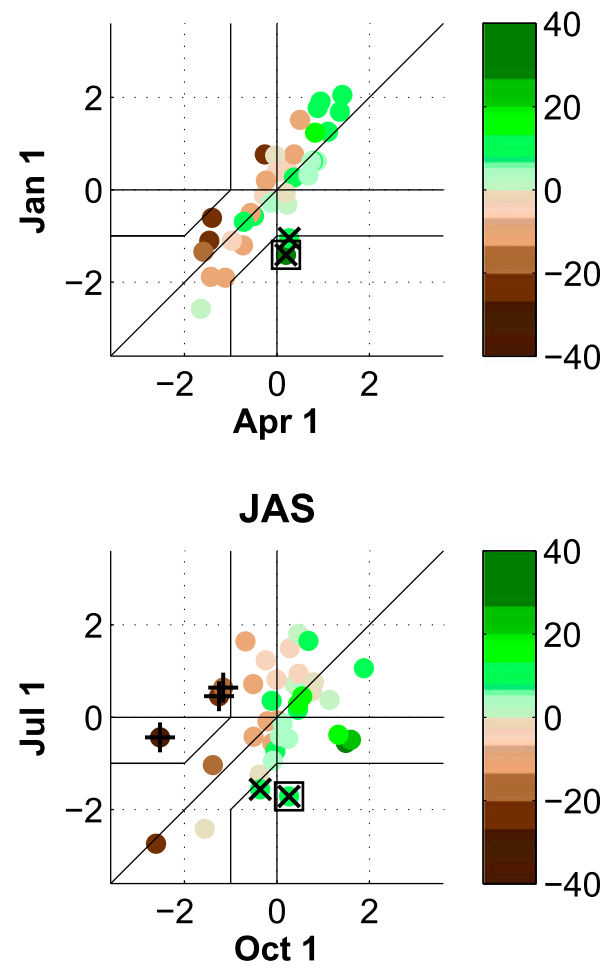

FIG. 6. Scatterplots of soil moisture at beginning of season ( $y$ axis) and end of season ( $x$ axis) plotted together with precipitation anomaly during the intervening season (color of the dots, scale at right; $\mathrm{mm} \mathrm{month} \mathrm{m}^{-1}$ ). Drought onsets are marked by + signs and terminations by $\times$ signs. Results are shown for the Noah model. A box is drawn if all three LSMs agree on onset and it two LSMs agree on termination. The lines in the upper left and bottom right enclose soil moisture transitions that classify as drought onsets and terminations, respectively.

drought termination might lead to increased runoff or, if dry soils can absorb the water, continued reductions in runoff. Figure 8 provides little support that, for the southern Plains, DO\&T can be driven by temperature variability that would cause variability of ET. High- and low-temperature anomalies (which would tend to induce soil moisture drying or moistening) are randomly scattered across the soil moisture drying and wetting events and there are no consistent temperature anomalies for DO\&T events.

\section{Large-scale atmosphere and ocean conditions associated with anomalies of soil moisture and change over time of soil moisture in the southern Plains}

Figure 9 shows the regression of 200-mb geopotential heights $(1 \mathrm{mb}=1 \mathrm{hPa})$ and SST (shown only where significant at the $5 \%$ level according to a two-sided $t$ test) on the time series of soil moisture anomalies at the start of each season. This is akin to many prior analyses of the causes of U.S. droughts (e.g., Seager 2015) and shows expected results: in winter, and to a lesser extent spring, positive soil moisture anomalies are favored by an El Niño state with a clear Rossby wave teleconnection that extends from twin anticyclones straddling the equatorial Pacific to a trough over the North Pacific and western North America. The trough favors westerly flow over the southern Plains and propagation of Pacific storms into the region (Seager et al. 2010). During summer and fall the association to tropical SSTs is absent. Instead in summer positive soil moisture is favored by a circulation anomaly with a low over the southern Plains but no obvious wave train and, in fall, by a clear circumglobal wave train that may originate over the western extratropical Pacific/East Asia region. In fall this wave places the southern Plains between a low to the west and a high to the east favoring southerly flow anomalies that would induce advection of warm, moist air from the south. Figure 9 also emphasizes the tropical Pacific connection by plotting together the southern Plains seasonal mean soil moisture anomalies with the corresponding seasonal 


\section{Seasonal Southern Plains NOAH Std SM Change, Avg Runoff (color)}

OND

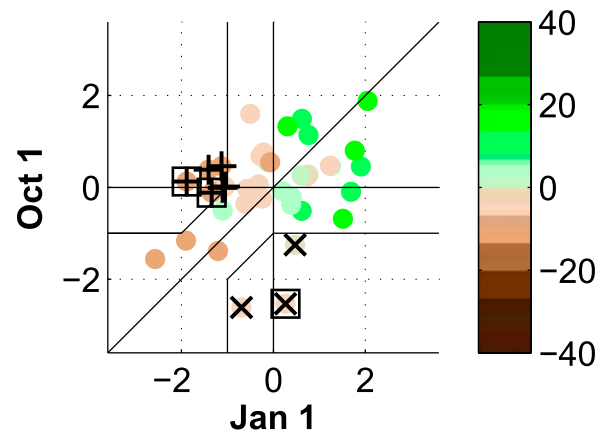

AMJ

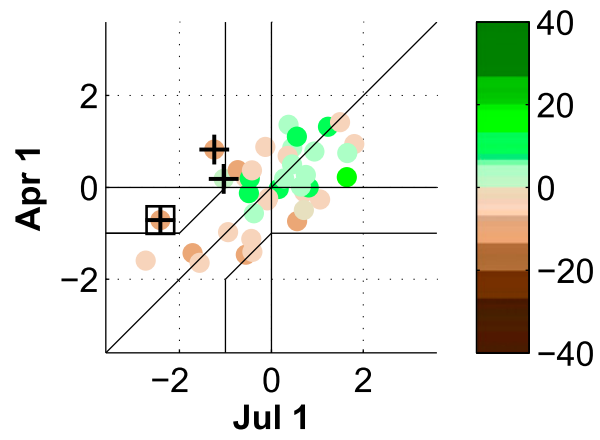

JFM

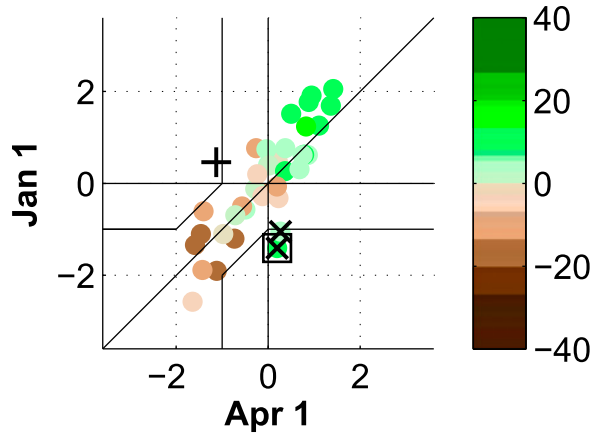

JAS

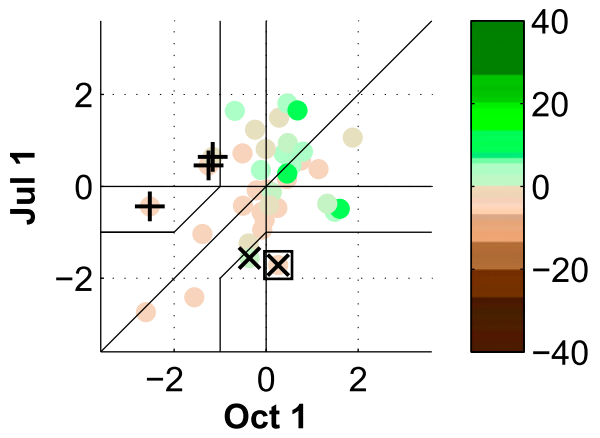

FIG. 7. As in Fig. 6, but for runoff (colors).

mean Niño-3.4 (SST anomalies averaged over $5^{\circ} \mathrm{S}-5^{\circ} \mathrm{N}$ and $170^{\circ}-120^{\circ} \mathrm{W}$ ) index (the correlation coefficient is 0.38 , significant at the $5 \%$ level). The general sweep up and down of the two seasonal mean time series is clear but also shows that the soil moisture retains much variability that is independent of the tropical Pacific Ocean variability.

The seasonal mean soil moisture history in Fig. 9 also shows some interesting aspects of DO\&T in the southern Plains. While some of the DO\&Ts (marked by colored dots) are not readily apparent in the seasonal mean soil moisture (because of averaging across the transition), the drought history of the southern Plains is clear here. There are many short-lived droughts, and two centered on 2000 and 2007 that had clear terminations. The most remarkable drought, however, was the extended one that lasted from 2010 to 2013. This drought began quickly in winter 2010/11 (see below) but there was no clear termination event. Instead, it ended by dribs and drabs with successive wetting events. Clearly in the southern Plains not all droughts start slowly and end quickly (cf. Mo 2011; Dettinger 2013).

In Fig. 10 we show the same regression but for change in soil moisture over the season. In this case the connection to tropical Pacific SSTs is essentially gone, even in winter. Statistically significant SST correlations are limited mostly to midlatitudes and where the circulation anomaly is of the sign that would force the SST anomalies (e.g., cold SST anomalies under westerly wind anomalies over the North Atlantic in OND, warm SST anomalies under southerly winds west of North America in AMJ). Instead, in all seasons, change in soil moisture is related to what appears to be midlatitude wave trains that place southerly flow over the Plains (although the summer pattern is ambiguous in this regard). The wave trains can have action over both the Pacific and Atlantic (e.g., OND) sectors. Here we also plot the time series of the anomalies in change in soil moisture over the season and precipitation in the intervening season. These show a remarkable level of agreement (the correlation coefficient is 0.68 , significant at the $1 \%$ level) highlighting the dominant driving of soil moisture change by precipitation. The soil moisture change time series is also marked with the drought onsets (brown circles) and terminations (green circles). The DO\&Ts correspond well to precipitation anomalies. The DO\&Ts were also marked on the time series of soil moisture anomalies and Niño-3.4 (Fig. 9). All three onsets do occur when the tropical Pacific is colder than normal but the terminations are not associated with warm 


\section{Seasonal Southern Plains NOAH Std SM Change, Avg Temp (color) \\ OND \\ JFM}

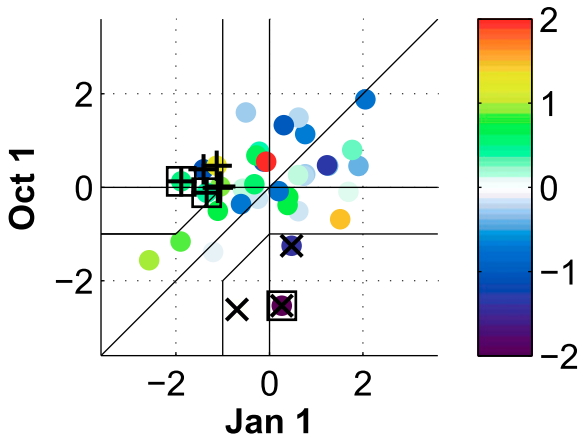

AMJ

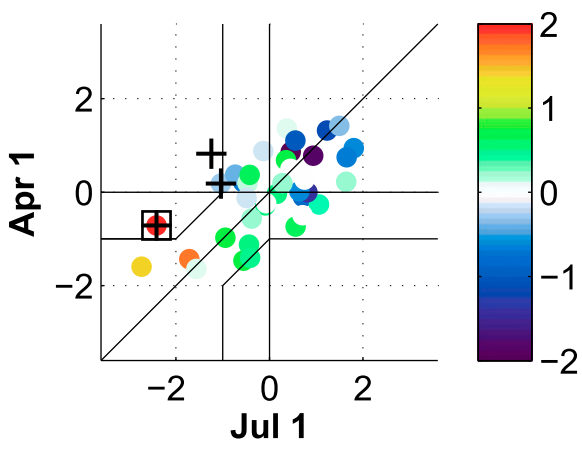

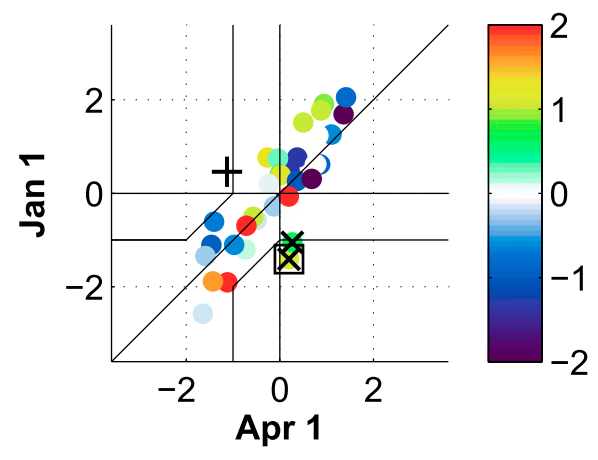

JAS

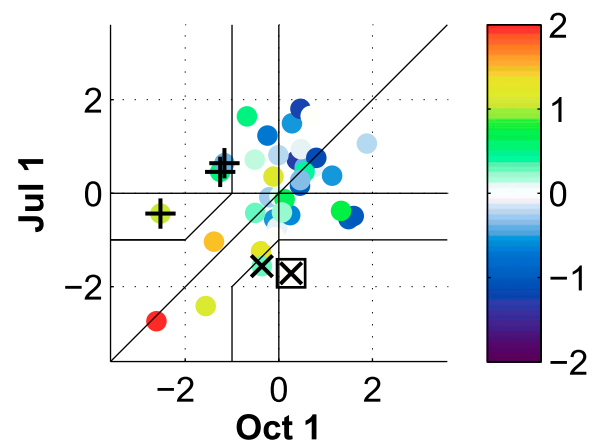

FIG. 8. As in Fig. 6, but for temperature (colors).

SST anomalies, again indicating the lack of a strong connection between soil moisture change and tropical Pacific SSTs. The stronger relation of SSTs to soil moisture than change over time of soil moisture can be understood because soil moisture is a quantity that integrates atmospheric forcing and is a lower-frequency quantity than change over time of soil moisture. The change is more influenced by higher-frequency precipitation variability likely related to internal atmospheric variability.

\section{Mechanisms of DO\&T for three drought onset and three drought termination events}

Figure 11 shows results for drought onsets in OND 2005, OND 2010, and AMJ 2012. In the left column we see widespread areas of soil moisture decline over the season that include, but need not be centered on, the southern Plains. These are well collocated with negative precipitation anomalies that are subcontinental in scale with areas of positive anomalies elsewhere over North America. In the region of precipitation and soil moisture declines, runoff declines (Fig. 11, center column) which will act as a stabilizing feedback on the soil moisture. In
AMJ 2012, the only one of these onsets to occur in a warm season, high-temperature anomalies (Fig. 11, center column) occurred centered over the central United States coincident with the location of soil moisture and precipitation decline. The height and moisture transport anomalies (Fig. 11, right column) show that in all three onsets there is a cyclonic anomaly over the southeastern United States and western Atlantic with northwesterly flow and, by examining the lengths of the moisture vectors, moisture divergence that will suppress precipitation over the southern Plains [see also Dong et al. (2011) for the case of fall and winter 2005/06].

Figure 12 shows the same set of results for the drought terminations. In JFM 1990 and OND 2000 positive precipitation anomalies were centered on the southeastern and southwestern Plains, respectively and drove increases in soil moisture (Fig. 12, left column). In JFM 1990 it also drove an increase in runoff but runoff remained below normal in OND 2000, a difference that is plausible depending on how excess precipitation is partitioned between soil moisture recovery, ET, and runoff. The JFM 1990 termination was accompanied by warm temperatures and the OND 2000 termination by 
Regr Seasonal Starts SM with Sig. SST (color), $200 \mathrm{mb} \phi$ (contours)

Oct 1

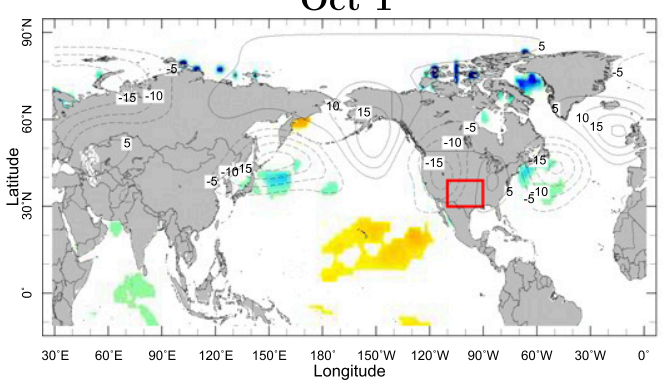

Apr 1

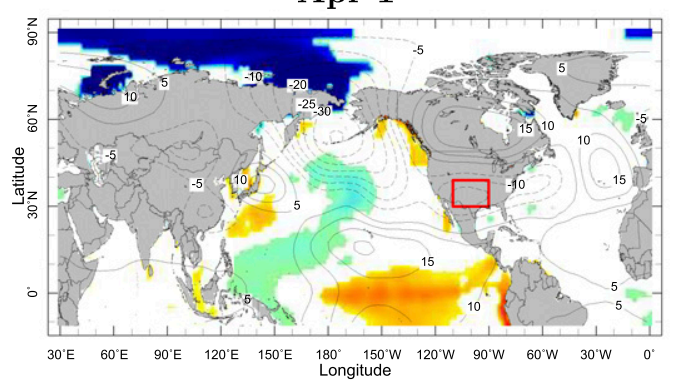

Jan 1

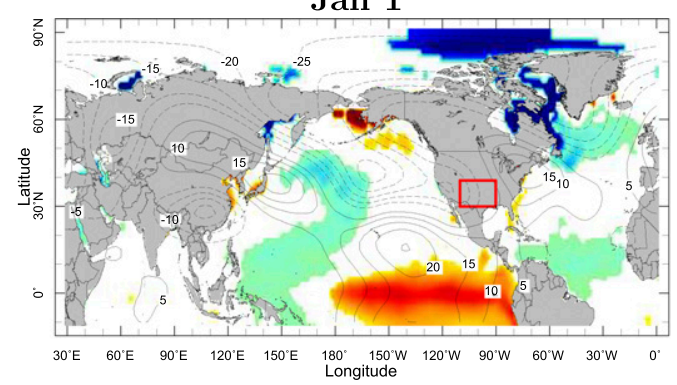

Jul 1

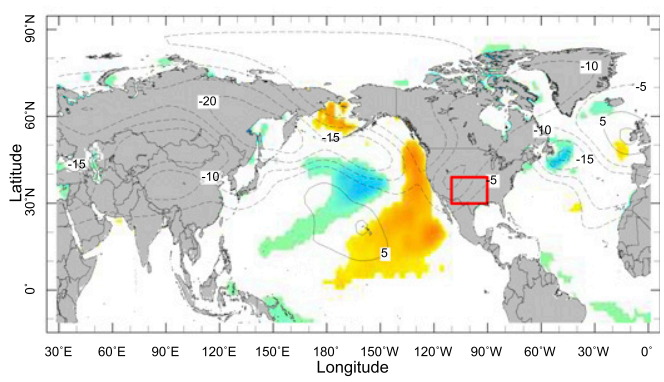

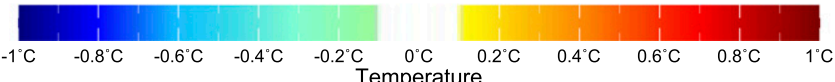

NINO 3.4 (black), Std Soil Moisture Southern Plains (grey)

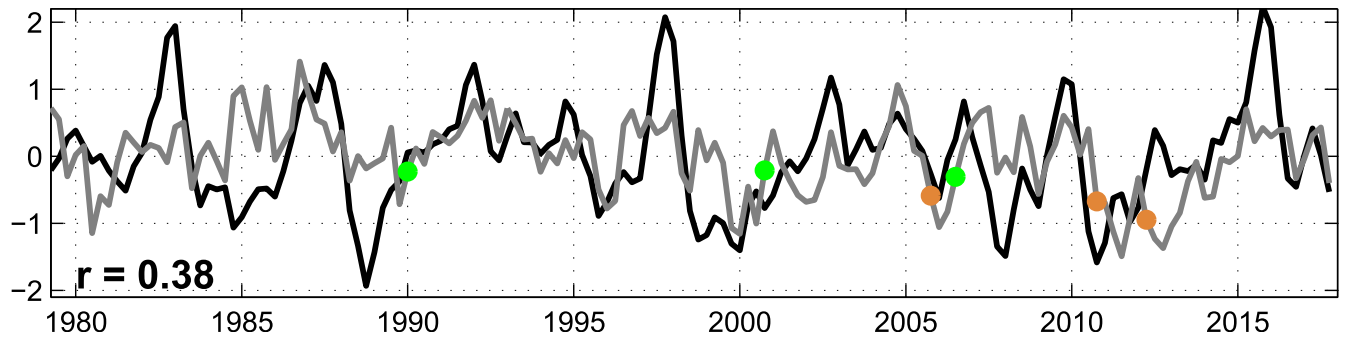

FIG. 9. The regression of 200-mb geopotential heights (contours; m) and SST (colors; K; only shown where significant at the $5 \%$ level according to a two-sided $t$ test) on soil moisture at the start of the season for (top left) 1 Oct, (top right) $1 \mathrm{Jan}$, (middle left) $1 \mathrm{Apr}$, and (middle right) $1 \mathrm{Jul}$. (bottom) Time series of standardized soil moisture anomaly and the Niño-3.4 index together with drought onsets as brown dots and terminations as green dots, according to the criteria described in the text, with their correlation coefficient marked at lower left.

cool temperatures, again illustrating the lesser importance of temperature than precipitation for DO\&T. The JAS 2006 termination is clear in soil moisture increase but the positive precipitation anomaly is centered in the southwest and not over locations of soil moisture increase in the southern Plains. The runoff and temperature anomalies in JAS 2006 are small. Southerly anomalies with moisture convergence occurred during the terminations of JFM 1990 and OND 2000 and, for the former event, are clearly associated with an anticyclone centered over the western Atlantic. Again the
JAS 2006 termination appears somewhat inconsistent, with no obvious circulation and moisture transport anomalies over the southwest or southern Plains inducing increases in positive precipitation and soil moisture.

Figure 13 then shows the larger-scale atmosphereocean context of the 6 DO\&T events. While we previously noted that the onsets occurred when the tropical Pacific was cool, only in OND 2010 were the SST anomalies strong and indicating a La Niña event. The wave train has some similarity, but also differences, with 
Regression SM Difference with Sig. SST (color), $200 \mathrm{mb} \phi$ (contours)
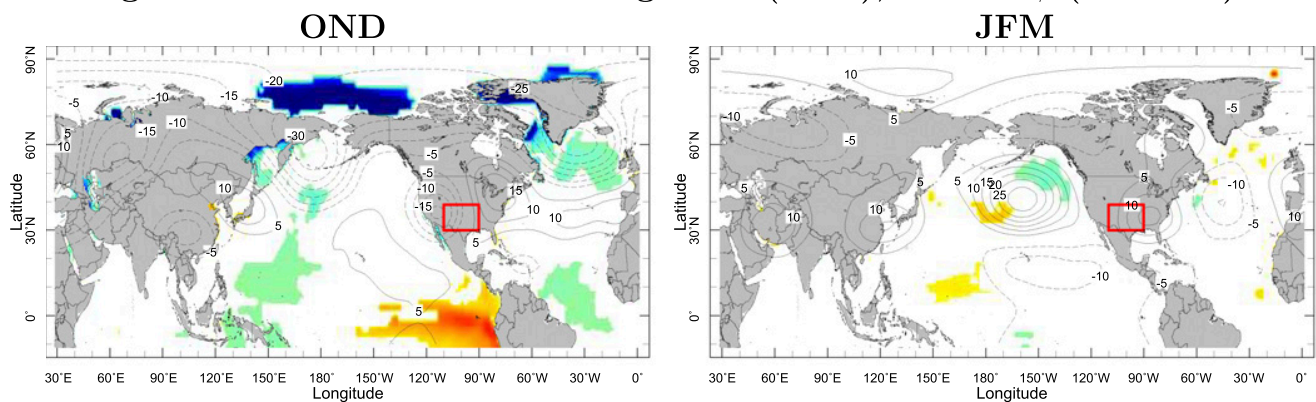

AMJ
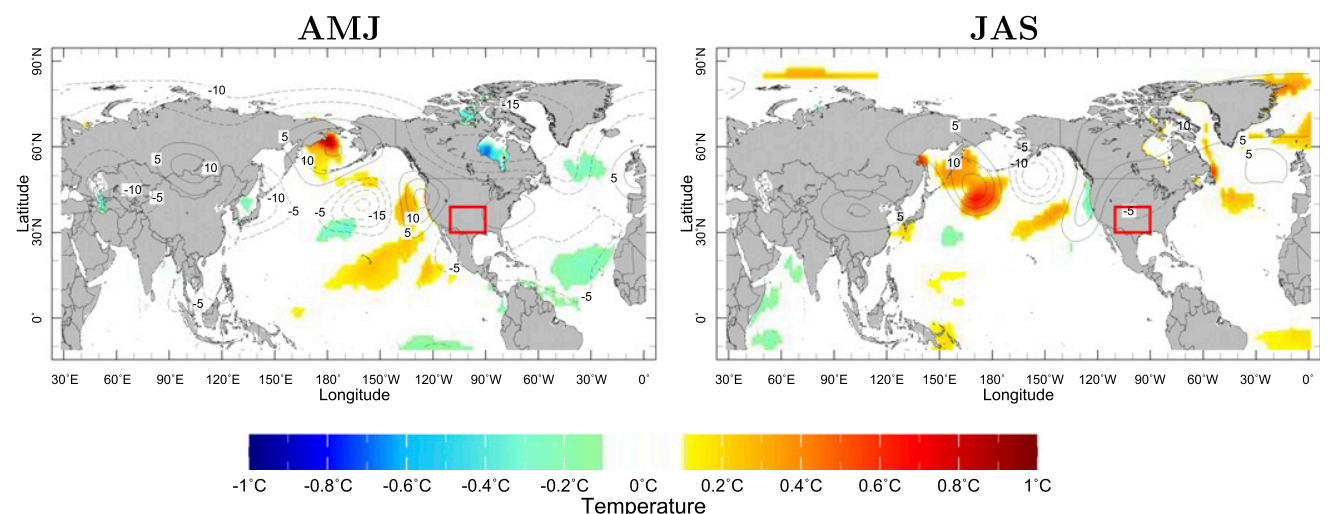

Std Southern Plains: Soil Moisture Change (black), Precip (grey)

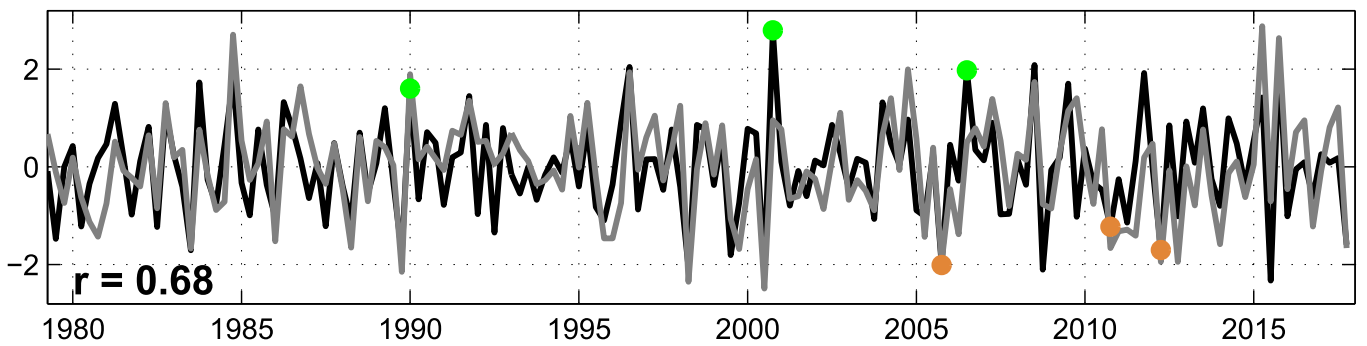

FIG. 10. As in Fig. 9, but for soil moisture change over the season and where the bottom panel plots time series of soil moisture change and precipitation.

the canonical La Niña pattern for fall (Seager et al. 2014a) and places strong northerly flow anomalies over the southern Plains. Adding to the evidence that the La Niña conditions led to drought onset, SST-forced models do produce dry conditions for this season (Seager et al. 2014a). However, the northerly flow over the Plains in this season seems additionally connected to a strong circulation anomaly over the Atlantic Ocean. AMJ 2012 has a very weak suggestion of forcing of drought onset from cold tropical Pacific SSTs although the circulation over North America is quite different to OND 2010 with a northeasterly wind anomaly over the southern Plains that would suppress precipitation. Drought onset in AMJ 2012 is more strongly connected to a circumglobal wave train. In OND 2005 there is only weak evidence of a drought onset-inducing circulation anomaly with a low over the southeast and northerly flow over the southern Plains. The terminations are clearly not related to SST forcing and, where significant, the SST anomalies are of the sign consistent with being generated by atmospheric forcing. Also clear is that the terminations can arise from very different circulation anomalies. In JFM 1990 the strong anticyclonic anomaly that led to southerly inflow and convergence of moisture over the southern Plains and drought termination was coupled with strong anticyclone over the North Pacific and east Asia and the midlatitude Atlantic Ocean and circumpolar low height anomalies to the northa pattern reminiscent of annular mode variability, though quite distinct from the northern annular mode 


\section{Seasonal Drought Onset}
Soil Moisture Change (contour) Precipitation (color)

\author{
Runoff (contour) \\ Temperature (color)
}

\author{
$700 \mathrm{mb}$ Height (color) \\ Moisture Transport (vector)
}

\section{OND 2005}
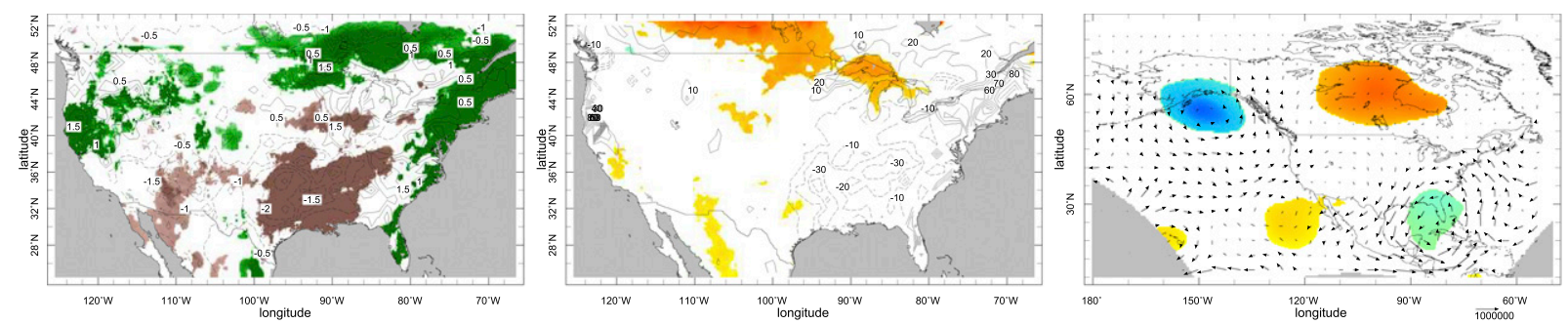

Oct-Dec 2005

height $2.0 \mathrm{~m}$ Time Oct-Dec 2005

\section{OND 2010}
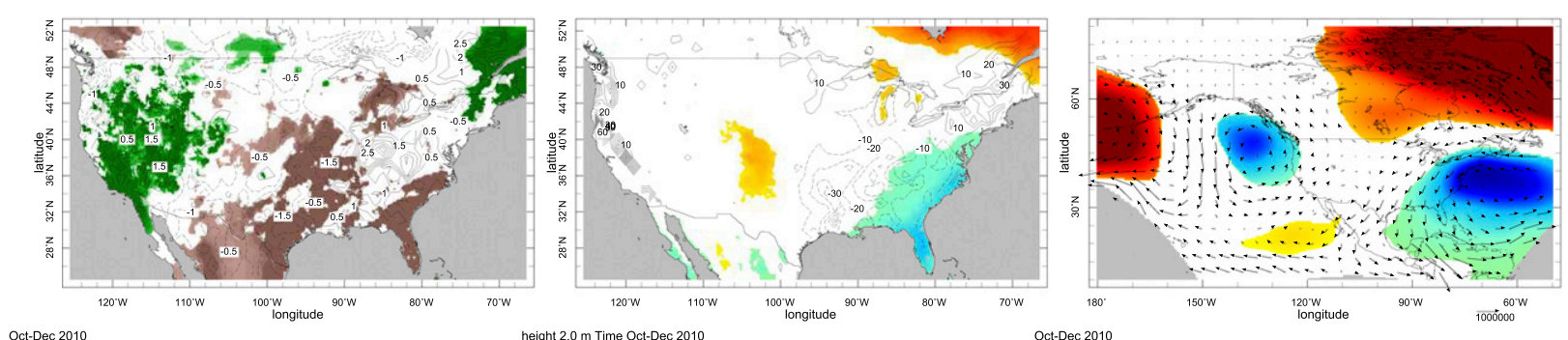

AMJ 2012

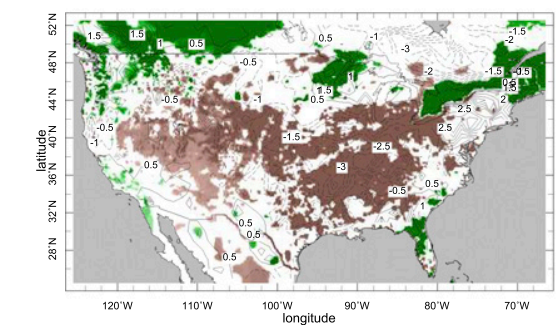

Apr-Jun 2012

height $2.0 \mathrm{~m}$ Time Oct-Dec 2010 Oct-Dec 2010
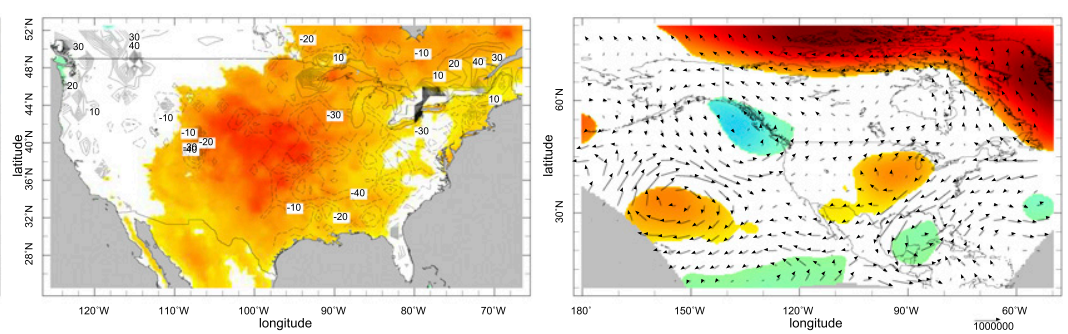

height $2.0 \mathrm{~m}$ Time Apr-Jun 2012

Apr-Jun 2012
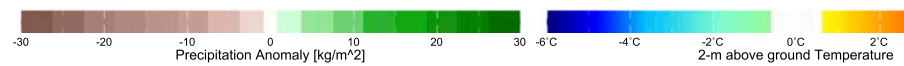

$-40 \quad \stackrel{-20}{-40} \stackrel{0}{20} \stackrel{40}{40}$

FIG. 11. Regional climate conditions for three drought onsets in (top) OND 2005, (middle) OND 2010, and bottom (AMJ 2012). (left) Anomalous change in soil moisture over the season (contours; $\mathrm{kg} \mathrm{m}^{-2}$ ) together with the precipitation anomaly during the season (colors; $\mathrm{kg} \mathrm{m}^{-2}$ ) . (center) The anomalies in runoff (contours; $\mathrm{kg} \mathrm{m}^{-2}$ ) and temperature (colors; $\mathrm{K}$ ) during the season. (right) The anomalies in 700-mb height (colors; $\mathrm{m}$ ) and vertically integrated moisture transport (vectors; reference label at bottom right; $\mathrm{kg} \mathrm{m}^{-1}$ ) during the season.

(Thompson and Wallace 2000). Curiously the termination in OND 2000 was associated with circulation anomalies that, in terms of their annular component, were opposite to those in the JFM 1990 termination.

\section{Drought onset in fall 2017}

In the late summer of 2017, according to the U.S. Drought Monitor (http://droughtmonitor.unl.edu), abnormally dry or drought conditions in the Southwest were restricted to coastal Southern California and southern Arizona. However, in the fall of 2017 the southwest and southern Plains became progressively dry, and by the beginning of 2018 dry to drought conditions covered essentially all of the southern Plains and interior Southwest. This drought worsened in winter and spring and continued into fall 2018. In our analysis only two of three LSMs agree that, by our criteria, fall 2017 was a drought onset and hence it was not included in the work described so far. However, its timeliness and 


\section{Seasonal Drought Termination}
Soil Moisture Change (contour) Precipitation (color)

\author{
Runoff (contour) \\ Temperature (color)
}

\author{
$700 \mathrm{mb}$ Height (color) \\ Moisture Transport (vector)
}
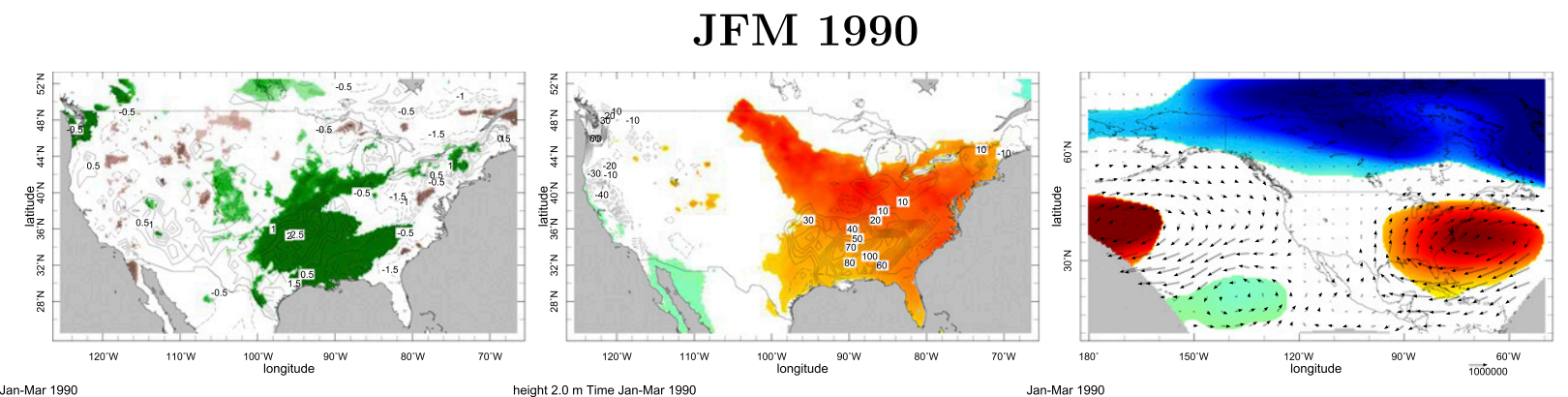

OND 2000
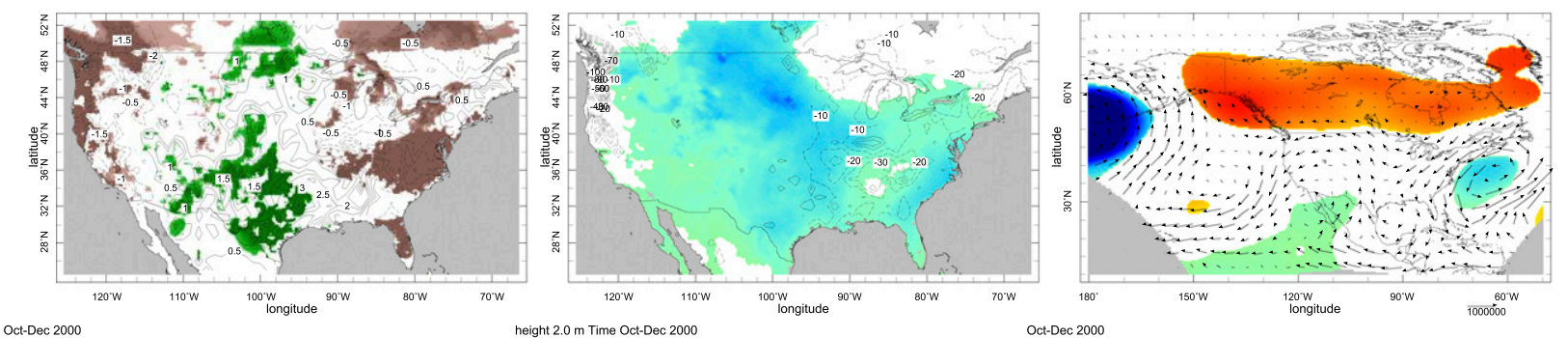

JAS 2006
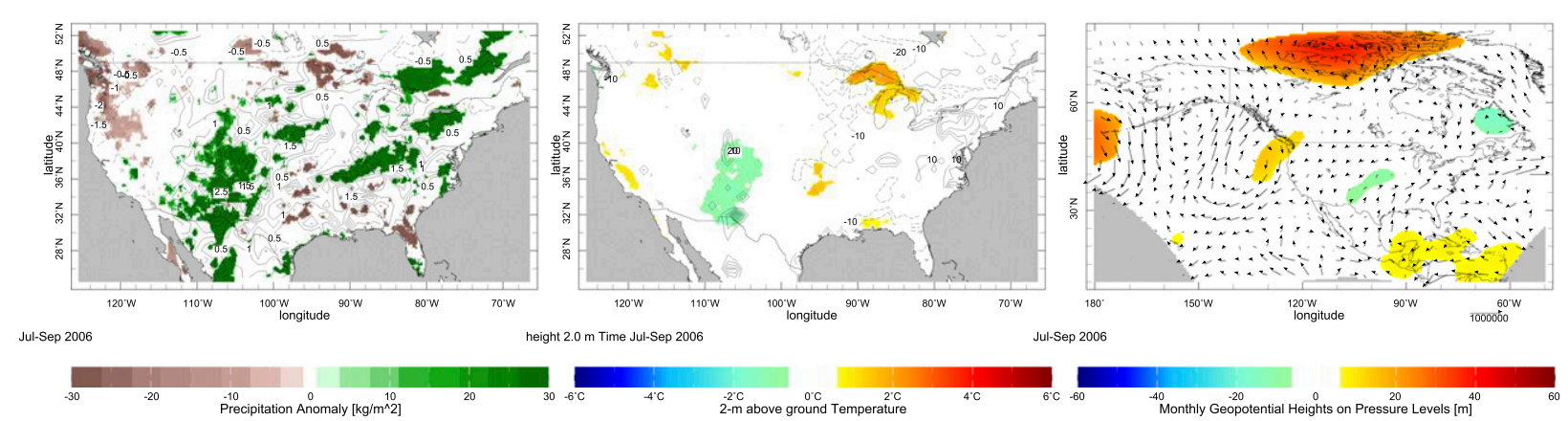

FIG. 12. As in Fig. 11, but for three drought terminations in (top) JFM 1990, (middle) OND 2000, and (bottom) JAS 2006.

agricultural impact justifies some attention now. Figure 14 shows the continental and large-scale conditions during the OND 2017 drought onset. The drought onset was caused by a drop of precipitation below normal across the southern United States, which caused widespread negative anomalies of soil moisture change (Fig. 14, top left). At the same time temperatures were above normal in the Southwest and northwest Mexico and runoff declined in the southeastern United States (Fig. 14, top right). These were related to a ridge of high pressure centered over the California-Arizona-Mexico border and, to its east, southerly flow and moisture divergence from the Southwest and southern Plains (Fig. 14, bottom left). In turn, this high was part of a wave train that spanned the northern extratropics while SSTs were cool in the equatorial Pacific and warm over the west Pacific warm pool, akin to La Niña conditions (Fig. 14, bottom right). Although we have provided some evidence for a connection of drought onset to La Niña conditions, it is not clear this was the case in OND 2017 because of no clear wave train that propagates from the equatorial Pacific to North America. However, this could have been one influence among others and really requires model experimentation to determine the origins of the planetary-scale circulation anomalies that caused the OND 2017 drought onset. 


\section{Seasonal Drought SST (color), $200 \mathrm{mb} \phi$ (contours) Onset Termination}
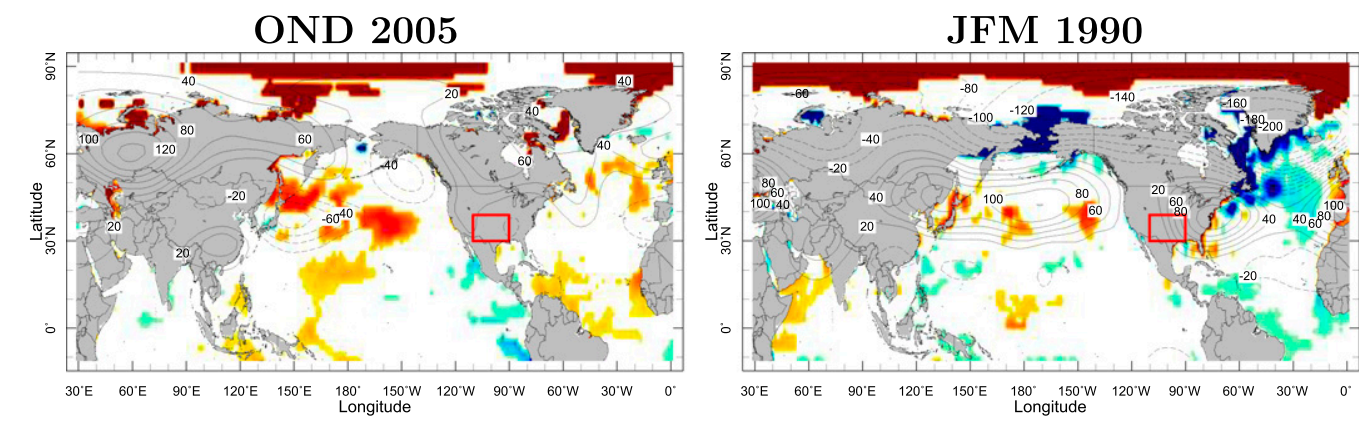

Oct-Dec 2005

OND 2010

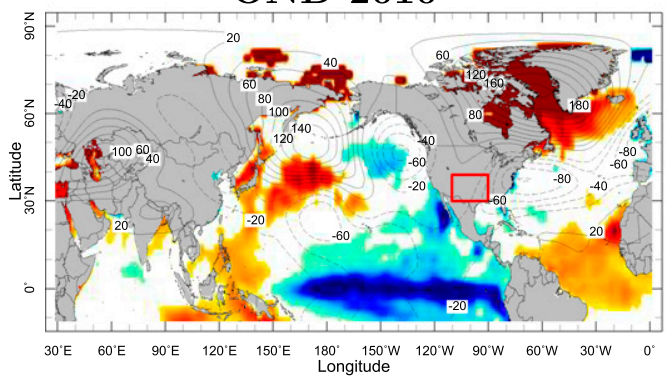

Jan-Mar 1990

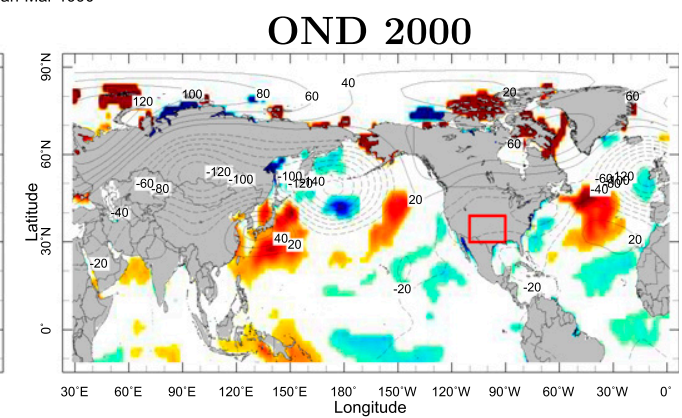

Oct-Dec 2010

Oct-Dec 2000
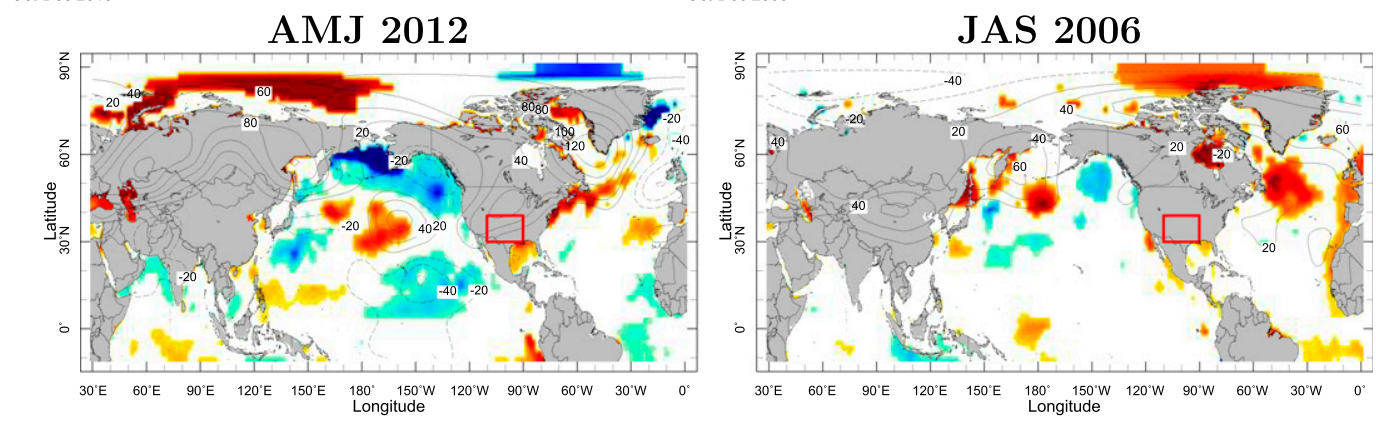

Apr-Jun 2012

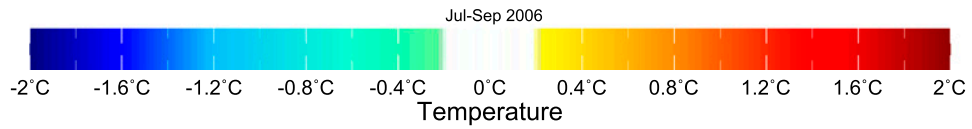

FIG. 13. Large-scale climate conditions during (left) drought onsets and (right) terminations. In each panel, contours show 200-mb height anomalies (m) and colors show SST anomalies (K). The red box shows the southern Plains region.

\section{Conclusions and discussion}

We have investigated the mechanisms that cause change in soil moisture at the seasonal time scale across North America and then focused in on attempting to explain onsets and terminations of droughts in the southern Plains using NLDAS-2 and regional and global Reanalysis data for the period since 1979. Conclusions are as follows.

- Anomalous soil moisture change over a season occurs within near continental-scale patterns that are closely related to the precipitation anomaly during the intervening season. The precipitation anomalies are related to atmospheric wave trains that span the North Pacific and North America. This is true for all seasons and in each season the southern Great Plains is a geographic center of hydrological change.

- In the southern Great Plains drought onset or termination can occur in any season but onsets are least likely in winter and terminations least likely in spring. Onsets are most likely in fall. While soil moisture in the southern Plains, which integrates atmospheric forcing, has a modestly close relationship to tropical 


\section{OND 2017}
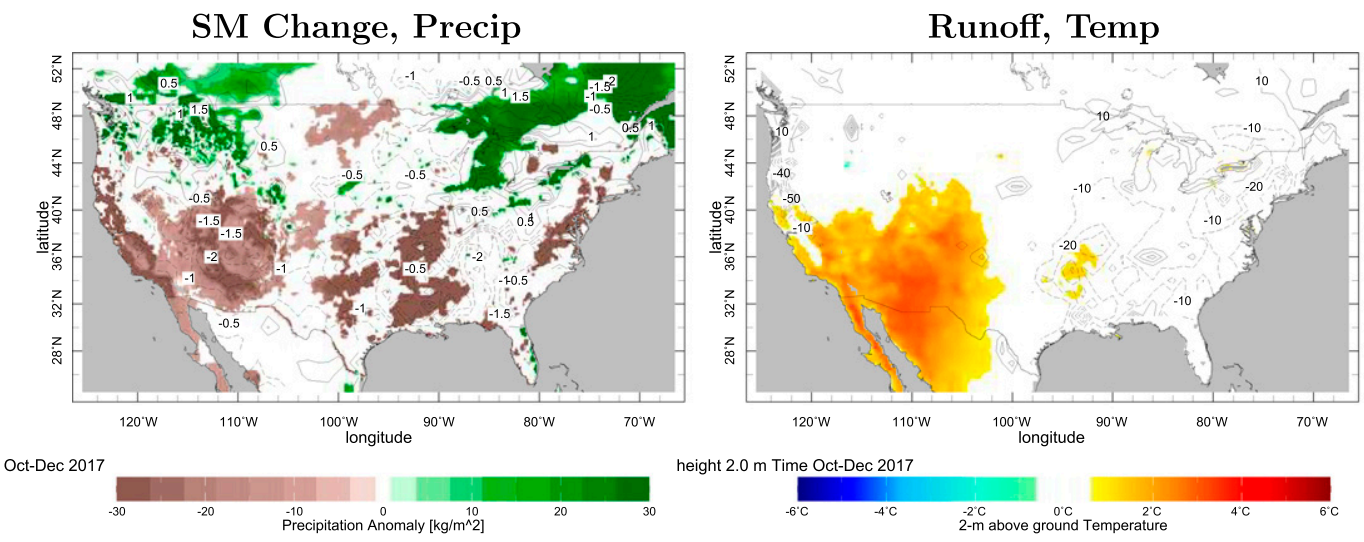

q Transport, $700 \mathrm{mb} \phi$

height $2.0 \mathrm{~m}$ Time Oct-Dec 2017
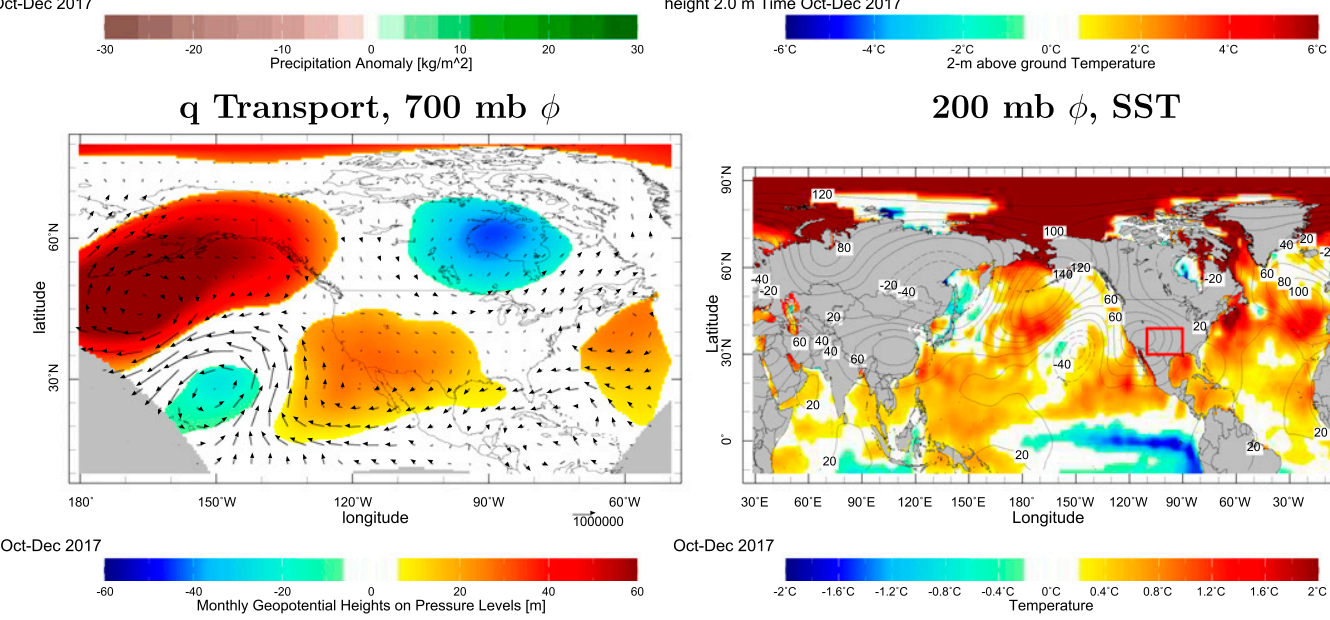

$200 \mathrm{mb} \phi, \mathrm{SST}$

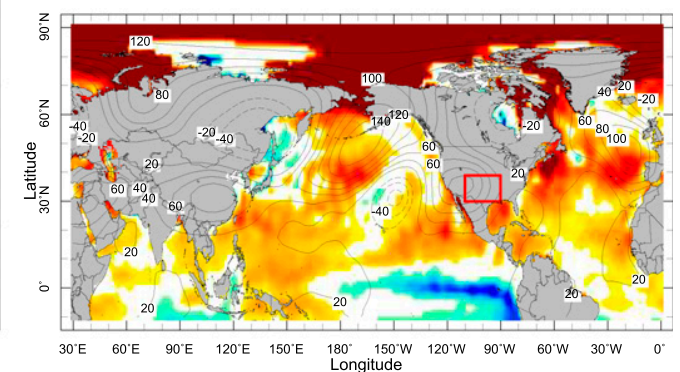

Oct-Dec 2017

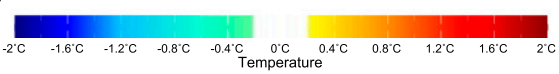

FIG. 14. Climate conditions during the OND 2017 drought onset in the southwest and southern Plains. (top left) The change over the season in soil moisture (standardized units; contours) and precipitation during the season (colors; $\mathrm{kg} \mathrm{m}^{-2}$ ). (top right) The seasonal anomalies of temperature (color; $\mathrm{K}$ ) and runoff (contours; $\mathrm{kg} \mathrm{m}^{-2}$ ). (bottom left) The anomalies in vertically integrated moisture transport (vectors; reference vector at bottom right; $\mathrm{kg} \mathrm{m}^{-1}$ ) and 700-mb geopotential heights (color; $\mathrm{m}$ ). (bottom right) SST anomalies (color over ocean; K) and 200-mb heights (contours; $\mathrm{m}$ ).

Pacific SST anomalies, the change in soil moisture is more closely related to internal atmospheric variability. There is little evidence of temperature anomalies driving hydrological change and drought onsets or terminations.

- For particular drought onsets and terminations it is found that they share common circulation and moisture transport anomalies that will favor wetting or drying but that these can be embedded within a variety of large-scale atmosphere-ocean climate anomalies. In some cases (e.g., OND 2010) there is clear driving for onset by cool tropical Pacific SST anomalies but in other onsets, and all terminations, analyzed there is no evidence of ocean driving. However, the southwest/southern Plains drought that began in the fall of 2017 (and which continued to the fall of 2018) may be a case in which onset was influenced by La Niña conditions in the tropical Pacific.
The work adds to our knowledge of DO\&T. Prior work on drought onset and recovery by Mo (2011) has considered multiple time scales and all of the United States. Using the ensemble mean of LSMs from the earlier generation of NLDAS, she found that drought onsets were quicker than demises across the United States including in the southern Plains. For seasonal time scales we find that drought onsets and terminations are equally as likely in the southern Plains. The difference is likely because Mo (2011) defined onset time as the months of precipitation deficit preceding the crossing of the drought threshold whereas we examine transitions from normal (between \pm 1 standardized units of soil moisture) to below normal conditions and the beginning conditions might already have been experiencing dry conditions. In agreement with Mo (2011) we find that for the southern Plains drought onset is rare in JFM but common in AMJ and OND and that drought termination is also rare in JFM but more common in JAS 
and OND. The dominance of precipitation in driving DO\&T extends this reality to the seasonal time scale from the subseasonal time scale for which this was previously shown by Mo and Lettenmaier (2016). The work improves understanding of the circulation anomalies responsible for DO\&T finding that anomalies that favor wetting or drying can occur by a variety of mechanisms but all involving wave trains in the Pacific-North America-Atlantic sector. El Niño and La Niña events can sometimes be responsible for the circulation anomalies that drive termination and onset of drought, respectively, but, consistent with the findings of Mo (2011), the correspondence is not strong.

The work reported indicates some clear directions for future research. One is that during some drought onsets and terminations (e.g., JAS 2006) there is little evidence in the seasonal means for the circulation anomaly that caused the change. Examining the subseasonal anomalies is needed since it is likely in these cases that drought onset and termination was caused by shorter-time-scale events that are obscured in the seasonal mean. The seasonality of drought onset and termination identified here-onset and termination unlikely in winter, terminations least likely in spring-is interesting and potentially useful but it needs to be checked if this persists in analysis of longer time periods of soil moisture. The model calibrated drought index of Williams et al. (2017), which is calibrated against the NLDAS-2 Noah soil moisture data used here, provides an opportunity to do this and extends back to 1895 . It is clear that SST-based prediction of drought onset and termination in the southern Plains will be of limited use. However, since it does appear as one influence on drought onset (at least), it should be examined for the potential predictability it offers and when and why this is. In terms of operational prediction systems, it also needs to be assessed if the models are correct in having limited influence of SST anomalies on DO\&T since, after all, too strong an ocean influence on hydrologic change would be a source of forecast error. If SST prediction will be of limited use, then it needs to be examined if atmosphere initial conditions can provide another source of predictability at the weather to subseasonal time scale including, as a lead example, any relation of precipitation over the southern Plains to the Madden-Julian oscillation (e.g., Zhou et al. 2012). The results presented here do not necessarily generalize beyond the southern Plains. It will be interesting to see if other regions where droughts are common (e.g., the Southwest and California) or have large impacts (e.g., the Midwest and agriculture) have similar or different mechanisms of drought onset and termination and similar or different mixes of predictability in terms of ocean forcing and atmospheric internal variability.
Acknowledgments. This work was supported by NOAA Award NA17OAR4310126 from the MAPP program and NSF Award AGS 1401400. We thank Justin Mankin and Naomi Henderson for acquiring and serving the NLDAS-2 data, the NOAA Drought Task Force members for useful comments on the work and three anonymous reviewers for their constructive criticisms. This is LDEO Contribution 8306.

\section{REFERENCES}

Basara, J. B., and J. I. Christian, 2018: Seasonal and interannual variability of land-atmosphere coupling across the Southern Great Plains of North America using the North American regional reanalysis. Int. J. Climatol., 38, 964-978, https://doi.org/ 10.1002/joc. 5223 .

Daly, C., W. P. Gibson, G. H. Taylor, G. L. Johnson, and P. Pasteris, 2000: High quality spatial climate data sets for the United States and beyond. Trans. ASAE, 43, 1957-1962, https://doi.org/10.13031/2013.3101.

Dettinger, M. D., 2013: Atmospheric rivers as drought busters on the U.S. West Coast. J. Hydrometeor., 14, 1721-1732, https:// doi.org/10.1175/JHM-D-13-02.1.

_ 2016: Historical and future relations between large storms and droughts in California. San Francisco Estuary Watershed Sci., 14, https://doi.org/10.15447/sfews.2016v14iss2art1.

Dong, X., and Coauthors, 2011: Investigation of the 2006 drought and 2007 flood extremes at the Southern Great Plains through an integrative analysis of observations. J. Geophys. Res., 116, D03204, https://doi.org/10.1029/2010JD014776.

Ford, T. W., S. M. Quiring, and O. W. Frauenfeld, 2017: Multidecadal variability of soil moisture-temperature coupling over the contiguous United States modulated by Pacific and Atlantic sea surface temperatures. Int. J. Climatol., 37, 1400-1415, https:// doi.org/10.1002/joc.4785.

Herweijer, C., R. Seager, and E. R. Cook, 2006: North American droughts of the mid to late nineteenth century: History, simulation and implications for medieval drought. Holocene, 16, 159-171, https://doi.org/10.1191/0959683606h1917rp.

Huang, H., R. Seager, and Y. Kushnir, 2005: The 1976/77 transition in precipitation over the Americas and the influence of tropical SST. Climate Dyn., 24, 721-740, https://doi.org/10.1007/ s00382-005-0015-6.

Jong, B., M. Ting, and R. Seager, 2016: El Niño's impact on California precipitation: Seasonality, regionality, and El Niño intensity. Environ. Res. Lett., 11, 054021, https:// doi.org/10.1088/1748-9326/11/5/054021.

Kam, J., J. Sheffield, X. Yuan, and E. F. Wood, 2013: The influence of Atlantic tropical cyclones on drought over the eastern United States. J. Climate, 26, 3067-3086, https://doi.org/ 10.1175/JCLI-D-12-00244.1.

Karl, T., F. Quinlan, and D. Ezell, 1987: Drought termination and amelioration: its climatological probability. J. Climate Appl. Meteor., 26, 1198-1209, https://doi.org/10.1175/1520-0450(1987) 026<1198:DTAAIC $>2.0$. CO;2.

Koster, R., and Coauthors, 2004: Regions of strong coupling between soil moisture and precipitation. Science, $\mathbf{3 0 5}, 1138-1140$, https://doi.org/10.1126/science.1100217.

Kumar, A., M. Chen, M. Hoerling, and J. Eischeid, 2013: Do extreme climate events require extreme forcings? Geophys. Res. Lett., 40, 3440-3445, https://doi.org/10.1002/grl.50657. 
Maxwell, J., J. T. Ortegren, P. A. Knapp, and P. T. Soule, 2013: Tropical cyclones and drought amelioration in the Gulf and southeastern coastal United States. J. Climate, 26, 8440-8452, https://doi.org/10.1175/JCLI-D-12-00824.1.

_, P. A. Knapp, J. T. Ortegren, D. L. Ficklin, and P. T. Soule, 2017: Changes in the mechanisms causing rapid drought cessation in the southeastern United States. Geophys. Res. Lett., 44, 12 476-12 483, https://doi.org/10.1002/2017GL076261.

McCabe, G. J., M. A. Palecki, and J. L. Betancourt, 2004: Pacific and Atlantic influences on multidecadal drought frequency in the United States. Proc. Natl. Acad. Sci. USA, 101, 4136-4141, https://doi.org/10.1073/pnas.0306738101.

Meng, L., and S. M. Quiring, 2010a: Examining the influence of spring soil moisture anomalies on summer precipitation in the U.S. Great Plains using the Community Atmosphere Model version 3. J. Geophys. Res., 115, D21118, https://doi.org/10.1029/ 2010JD014449.

— temperatures and precedent soil moisture with summer precipitation in the U.S. Great Plains. Int. J. Climatol, , 30, 884 893, https://doi.org/10.1002/joc.1941.

Mercier, S., 2018: The impact of La Niña on the current agricultural outlook. AgWeb, accessed 31 August 2018, https:// www.agweb.com/blog/straight-from-dc-agricultural-perspectives/ the-impact-of-la-nina-on-the-current-agricultural-outlook/.

Mesinger, F., and Coauthors, 2006: North American Regional Reanalysis. Bull. Amer. Meteor. Soc., 87, 343-360, https://doi.org/ 10.1175/BAMS-87-3-343.

Mo, K. C., 2011: Drought onset and recovery over the United States. J. Geophys. Res., 116, 168, https://doi.org/10.1029/2011JD016168.

— over the United States. J. Hydrometeor., 17, 1169-1184, https://doi.org/10.1175/JHM-D-15-0158.1.

Namias, J., 1955: Some meteorological aspects of drought with special reference to the summers of 1952-54 over the United States. Mon. Wea. Rev., 83, 199-205, https://doi.org/10.1175/ 1520-0493(1955)083<0199:SMAOD>2.0.CO;2.

Schubert, S. D., M. J. Suarez, P. J. Pegion, R. D. Koster, and J. T. Bacmeister, 2004a: Causes of long-term drought in the United States Great Plains. J. Climate, 17, 485-503, https://doi.org/ 10.1175/1520-0442(2004)017<0485:COLDIT>2.0.CO;2.

,,,,---- and,$- 2004 \mathrm{~b}$ : On the cause of the 1930s Dust Bowl. Science, 303, 1855-1859, https://doi.org/10.1126/ science.1095048.

,,,---- , and,- 2008 : Potential predictability of longterm drought and pluvial conditions in the U.S. Great Plains J. Climate, 21, 802-816, https://doi.org/10.1175/2007JCLI1741.1.

— - and Coauthors, 2009: A U.S. CLIVAR project to assess and compare the responses of global climate models to droughtrelated SST forcing patterns: Overview and results. J. Climate, 22, 5251-5272, https://doi.org/10.1175/2009JCLI3060.1.

Seager, R., 2015: Decadal hydroclimate variability across the Americas. Climate Change: Multidecadal and Beyond, C.-P. Chang et al., Eds., World Scientific Publishing, 235-254, https://doi.org/10.1142/9789814579933_0015.

_ and M. P. Hoerling, 2014: Atmosphere and ocean origins of North American drought. J. Climate, 27, 4581-4606, https:// doi.org/10.1175/JCLI-D-13-00329.1.

_, Y. Kushnir, C. Herweijer, N. Naik, and J. Velez, 2005: Modeling of tropical forcing of persistent droughts and pluvials over western North America: 1856-2000. J. Climate, 18, 4065-4088, https://doi.org/10.1175/JCLI3522.1.
— - - M. Ting, M. A. Cane, N. Naik, and J. Velez, 2008: Would advance knowledge of 1930s SSTs have allowed prediction of the Dust Bowl drought? J. Climate, 21, 3261-3281, https://doi.org/10.1175/2007JCLI2134.1.

— - A. Tzanova, and J. Nakamura, 2009: Drought in the southeastern United States: Causes, variability over the last millennium and the potential for future hydroclimate change. J. Climate, 22 , 5021-5045, https://doi.org/10.1175/2009JCLI2683.1.

_, N. Naik, M. A. Cane, N. Harnik, M. Ting, and Y. Kushnir, 2010: Adjustment of the atmospheric circulation to tropical Pacific SST anomalies: Variability of transient eddy propagation in the Pacific-North America sector. Quart. J. Roy. Meteor. Soc., 136, 277-296, https://doi.org/10.1002/qj.588.

- L. Goddard, J. Nakamura, N. Naik, and D. Lee, 2014a: Dynamical causes of the 2010/11 Texas-northern Mexico drought. J. Hydrometeor., 15, 39-68, https://doi.org/10.1175/ JHM-D-13-024.1.

, D. Neelin, I. Simpson, H. Liu, N. Henderson, T. Shaw, Y. Kushnir, and M. Ting, 2014b: Dynamical and thermodynamical causes of large-scale changes in the hydrological cycle over North America in response to global warming. J. Climate, 27, 7921-7948, https://doi.org/10.1175/JCLI-D-14-00153.1.

Siler, N., Y. Kosaka, S. Xie, and X. Li, 2017: Tropical ocean contributions to California's surprisingly dry El Niño of 2015/16. J. Climate, 30, 10 067-10 079, https://doi.org/10.1175/JCLI-D17-0177.1.

Thompson, D. W. J., and J. M. Wallace, 2000: Annular modes in the extratropical circulation: Part I: Month-to-month variability. J. Climate, 13, 1000-1016, https://doi.org/10.1175/1520-0442(2000) 013<1000:AMITEC $>2.0 . C O ; 2$.

Trenberth, K., G. Branstator, and P. Arkin, 1988: Origins of the 1988 North American drought. Science, 242, 1640-1645, https://doi.org/10.1126/science.242.4886.1640.

Williams, A. P., B. Cook, J. E. Smerdon, D. A. Bishop, R. Seager, and J. S. Mankin, 2017: The 2016 southeastern US drought: an extreme departure from centennial wetting and cooling. J. Geophys. Res. Atmos., 122, $10888-10$ 905, https://doi.org/ 10.1002/2017JD027523.

Xia, Y., and Coauthors, 2012a: Continental-scale water and energy flux analysis and validation for the North American Land Data Assimilation System project phase 2 (NLDAS-2): 1. Intercomparison and application of model products. J. Geophys. Res., 117, D03109, https://doi.org/10.1029/2011JD016048.

, and Coauthors, 2012b: Continental-scale water and energy flux analysis and validation for North American Land Data Assimilation System project phase 2 (NLDAS-2): 2. Validation of model-simulated streamflow. J. Geophys. Res., 117, D03110, https://doi.org/10.1029/2011JD016051.

_ J. Sheffield, M. B. Ek, J. Dong, N. Chaney, and H. Wei, 2014: Evaluation of multi-model simulated soil moisture in NLDAS-2. J. Hydrol., 512, 107-125, https://doi.org/10.1016/ j.jhydrol.2014.02.027.

, M. B. Ek, Y. Wu, T. Ford, and S. M. Quiring, 2015: Comparison of NLDAS-2 simulated and NASMD observed daily soil moisture. Part I: Comparison and analysis. J. Hydrometeor., 16, 1962-1980, https://doi.org/10.1175/ JHM-D-14-0096.1.

Zhou, S., M. L'Heureux, S. Weaver, and A. Kumar, 2012: A composite study of the MJO influence on the surface air temperature and precipitation over the continental United States. Climate Dyn., 38, 1459-1471, https://doi.org/10.1007/ s00382-011-1001-9. 